\title{
Economic Structural Change and Freight Transport Demand in China
}

Xun $\mathrm{Xu},{ }^{1}$ Tianduo Peng 


\section{About KAPSARC}

The King Abdullah Petroleum Studies and Research Center (KAPSARC) is a non-profit global institution dedicated to independent research into energy economics, policy, technology and the environment across all types of energy. KAPSARC's mandate is to advance the understanding of energy challenges and opportunities facing the world today and tomorrow, through unbiased, independent, and high-caliber research for the benefit of society. KAPSARC is located in Riyadh, Saudi Arabia.

This publication is also available in Arabic.

\section{Legal Notice}

(C) Copyright 2020 King Abdullah Petroleum Studies and Research Center ("KAPSARC"). This Document (and any information, data or materials contained therein) (the "Document") shall not be used without the proper attribution to KAPSARC. The Document shall not be reproduced, in whole or in part, without the written permission of KAPSARC. KAPSARC makes no warranty, representation or undertaking whether expressed or implied, nor does it assume any legal liability, whether direct or indirect, or responsibility for the accuracy, completeness, or usefulness of any information that is contained in the Document. Nothing in the Document constitutes or shall be implied to constitute advice, recommendation or option. The views and opinions expressed in this publication are those of the authors and do not necessarily reflect the official views or position of KAPSARC. 


\section{Key Points}

hina's rapidly rising freight transport demand has been one of the primary contributors to global oil consumption growth since 2000 and has remained the dominant source of the country's domestic transport energy demand. Despite its obvious importance to the world oil market, little research has been devoted to understanding freight demand in China. This contrasts with the focus given to passenger mobility demand in this country. This paper uses detailed input-output and freight transport data to analyze the main structural driving forces of China's freight transport demand from 1997-2012, the period in which it experienced its fastest growth. It then combines the obtained results with the latest available data to offer insights into possible future scenarios of freight transport demand in the world's second-largest economy.

The transport of bulk commodities has historically been the largest-growing freight sector. However, the surging freight volumes from 1997-2012 were largely due to demand from the fast-growing construction and machinery, electrical and transport equipment sectors.

Demand changes in the production sectors are also being driven by the structural evolvement of end-use demand, namely exports, capital formation, and rural, urban and government consumption. Capital formation and exports were the two largest demand drivers of freight transport activities from 1997-2012.

In-depth analysis suggests that the growth of total final demand has been the largest contributor to freight transport demand growth. Other factors, such as economic structural changes, lengthening production linkages and changes in the transport modal mix, have also played important roles.

Analysis using data from 2017 suggests that economic structural changes and production linkage variation have become negative catalysts of freight activity growth.

The Chinese economy is shifting to a consumption-driven model, with its industrial focus transitioning to the high-value manufacturing and services sectors. The trend in dematerialization as a result of these structural changes may slow freight transport demand growth in the coming decades.

China's actual (solid line) and estimated (dash line) mode-specific tonne-kilometers, 1997-2020

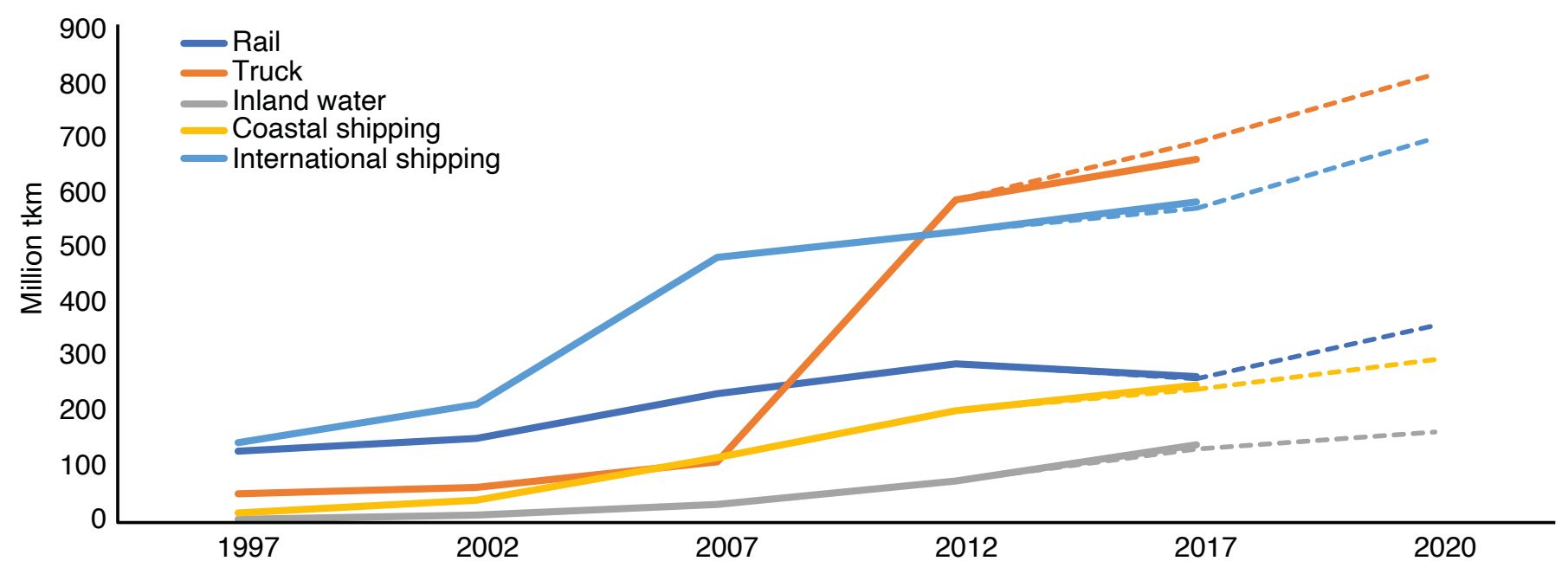




\section{Summary}

A

fter decades of rapid economic

development, China is quickly becoming

the world's second-largest transport

energy consumer. Recently, it has also surpassed the United States (U.S.) as the world's largest oil importer, and it is expected to become the largest oil consumer by the early 2030s. Despite the growing importance of China as a leading transport energy consumer and carbon emitter, freight transport demand has accounted for most transport energy demand in China over the last 40 years but remains poorly understood. Freight is a derived demand from the economy. Over the last few decades, the Chinese economy has not only expanded substantially, its structure has also changed considerably. While the share of primary and low value-added secondary sectors has decreased, high value-added secondary sectors and tertiary sectors have expanded steadily. China is expected to become the world's largest economy around 2030. As its structure continues to evolve, it is important to understand how its structural changes will impact freight transport demand. This impact will also have implications for its transport energy demand and carbon emissions mitigation strategy.

This paper utilizes an input-output approach and conducts an accounting analysis of China's freight transport demand from 1997-2012, its fastest period of growth. It quantifies the effects of key drivers of freight transport activities growth and explores the room for policy intervention to improve the efficiency of the freight logistics system. Simulations of likely future scenarios are also conducted, accounting for combined changes in each determining factor.

Two key perspectives of the economic structure, the production sectors and the end users, are considered in the analysis. Economic structural change is caused by the combined effects of the changing distribution of end-use demands within the economy and the shifting expenditure on commodities and services by end users. The ultimate result is reflected as an evolution of the economy's production structure.

Observed freight activities in the goods producing sectors are allocated to all the downstream production sectors, the ultimate demand source of the transported goods, through an input-output analysis. The result suggests that, while the transportation of bulk commodities has seen the largest growth overall, the fast-growing construction and machinery, electrical and transport equipment sectors accounted for the fastest growth in demand from 1997-2012. Capital formation and exports were the two largest end-use drivers of freight transport activities, whereas the role of private household consumption (urban and rural) decreased during this period.

An in-depth structural decomposition analysis considers more determinants of freight movement from both the demand and supply sides. This includes the level of total final demand, inter-industry production linkages in the supply chain, the economy's production structure, its transport modal mix, and freight transport intensity. Growth of total final demand is found to be the largest driver of China's freight transport demand growth between 1997 and 2012. The lengthening production linkages and the growing share of end users, who had more freight-intensive expenditures, also played important roles during this time. The reduction in freight transport intensity, on the other hand, is found to have had the largest negative impact on freight demand growth.

With weak external demand and slower gross domestic product (GDP) growth since 2012, China's economy has been gradually moving toward a 
consumption-led development model, with its industries increasingly focused on the high value-added manufacturing and services sectors. Analyses of future scenarios using the latest available data suggest that the slowdown in total final demand growth has been the leading cause of the slowdown in freight growth. The main structural aspects of the economy have also pivoted toward less freight-intensive consumption and production. Policymakers need to be aware of the pace of this dematerialization trend and its potential negative impact on China's freight transport demand in the long run. 
ollowing decades of rapid economic development, China is now the world's second-largest transport energy consumer, behind the United States (U.S.) (Figure 1). Key drivers of this change are strong industrialization, urbanization, and income growth, which have led to a rapid improvement of living conditions in the country. China's fast rise to be one of the world's top transport energy consumers has important implications for the international energy market and the environment. Globally, transport is the largest oil-consuming sector (IEA 2017a). Since 2000 , China has been the largest driver of global oil consumption growth and is projected to remain a major driver of world oil demand over the next two decades (IEA 2018b). Recently, it has also surpassed the U.S. as the world's largest oil importer and is expected to become the largest oil consumer in the 2030s (IEA 2018b). Meeting China's future transport energy demand is, therefore, one of the most important issues facing decision-makers concerned about world energy markets.

Figure 1. China's GDP and freight movement growth $(1995=1)$ and the U.S. and China's shares of global transport energy consumption (right axis) (1995-2015).

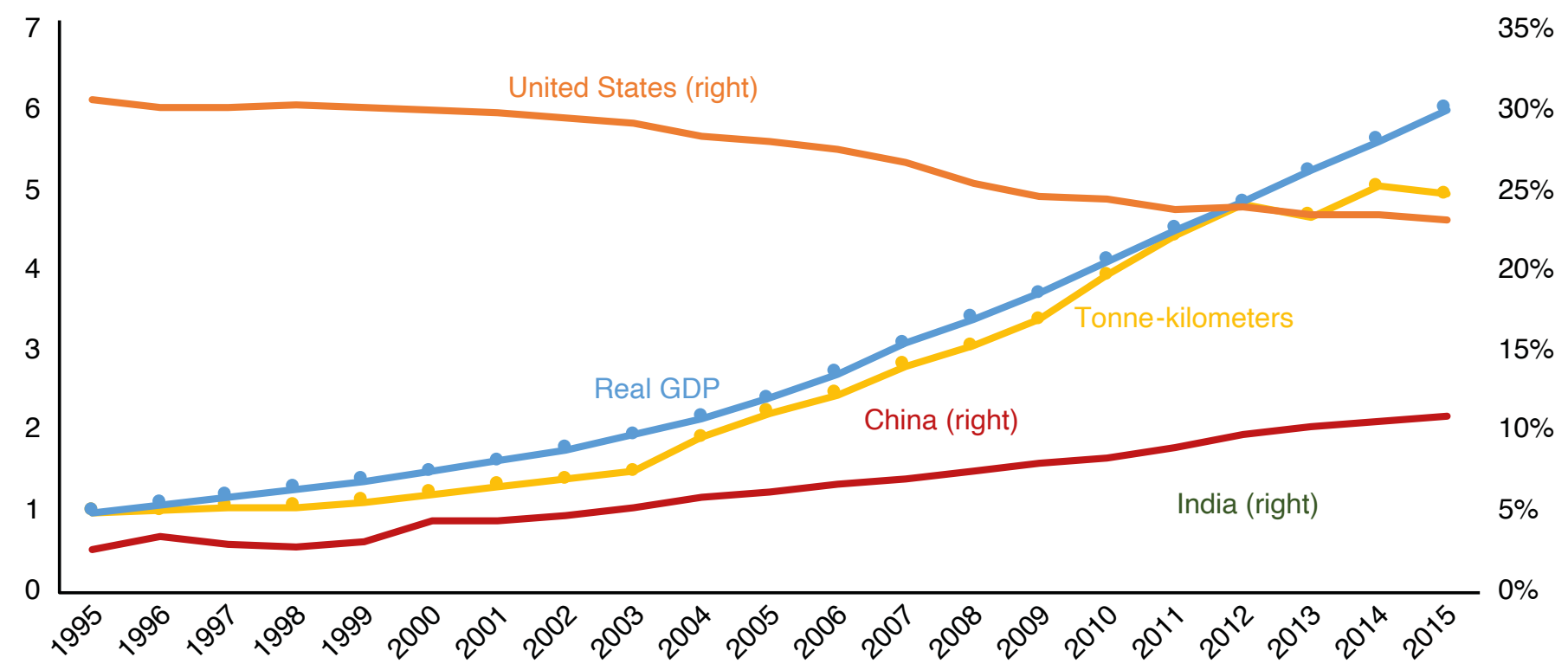

Sources: IEA (2018a), China Statistical Yearbook (2019), and World Bank (2019), and calculated by the authors.

The global transport sector accounts for about a quarter of all fossil fuel carbon dioxide $\left(\mathrm{CO}_{2}\right)$ emissions (IEA 2019). China, the world's largest $\mathrm{CO}_{2}$ emitter, has committed to the 2015 Paris Agreement on climate change and has taken various measures to implement this commitment. Emissions from China's transport sector are projected to maintain their current growth into the 2040s (IEA 2017b), while all other sectors are expected to reach peak energy-related $\mathrm{CO}_{2}$ emissions before 2030. The continual growth in China's $\mathrm{CO}_{2}$ emissions reflects its rising demand for transport and poses a significant challenge to its carbon emissions reduction agenda. 
Despite the growing importance of China as a leading transport energy consumer and carbon emitter, several of the fundamental determinants of its transport energy demand remain poorly understood. There are important differences between the determinants of energy consumed for passenger mobility and freight movement. As China has witnessed the fastest growth of energy consumption for passenger mobility in recent years, it has been at the forefront of public policy debate. However, freight activity has been the largest source of transport energy demand in the country over the last four decades, but it has received much less policy and research attention. Further, passenger transport has had increasing non-conventional fuel options and policy initiatives that have helped curb the growth of motor gasoline consumption. In contrast, freight transport has limited fuel alternatives due to technology, infrastructure, and market constraints. Thus, freight transport is projected to have higher oil demand growth than passenger transport in the coming years (IEA 2017b).

There is substantial research focused on passenger travel demand, but much less attention is given to freight transport. Freight is a derived demand of the economy (Tavasszy and De Jong 2013). Over the last few decades, China's economy has expanded substantially and its structure has changed considerably. It has quickly moved up the global value chain, transforming itself from an exporter of primary resource commodities and low-value consumer products into one of the world's strongest industrial powerhouses. These changes have had profound effects on its demand for freight. The Chinese economy is expected to become the world's largest around 2030, and its main components continue to evolve (IMF 2018). It is thus critically important to understand how the structural changes in its economy will impact its freight demand, its overall transport energy consumption and its carbon emissions mitigation strategy.

To this end, this paper utilizes an extended input-output (IO) approach and conducts an accounting analysis of China's freight mobility during its fastest period of growth, in order to investigate the economic demand drivers of its freight movement growth. Since freight is also determined by the supply of transport services, the effects of several other factors are also considered and quantified in order to explore potential room for policy intervention. Simulations are conducted to project future freight transport volume under likely economic scenarios.

The rest of the paper is structured as follows. Section 2 describes the methodologies and data used in this research. Section 3 demonstrates how freight transport growth during the period analyzed was shaped by structural changes in production and end use in the Chinese economy. Section 4 discusses the results of the structural decomposition analysis, which further delineates the separate impact of various freight determinants. Section 5 discusses the results of the simulations to estimate the latest freight transport demand. The last section provides concluding remarks. 


\section{Methodology and Data}

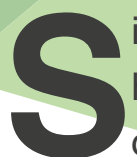

ince the second half of the 1990s, China has witnessed extraordinary growth in its domestic and international freight transport. The fastest growth occurred from 1997-2012, as the rise of aggregate freight tonne-kilometers (tkm) (for road, railway, inland, coastal and international maritime shipping) closely followed the rapid expansion of the country's economy (Figure 1).

The swift development of China's economy during this period was fueled by a series of major economic reforms and policy initiatives. During the late 1990s, China initiated a wave of industrial reforms to privatize and downsize the state-owned enterprise sector. Around the same time, the once public-sector-dominated urban housing system began to be privatized, and commercial property development was heavily promoted. In response to the 1997 Asian financial crisis, the Chinese government accelerated the development of public infrastructure in an effort to boost the country's economic growth. China joined the World Trade Organization (WTO) in 2001 and became deeply integrated into the global supply chain. This led to a rapid rise in China's foreign trade and the swift growth of its economy in the years that followed. After the 2008 global financial crisis, the Chinese government renewed its efforts to promote domestic demand by launching a $\$ 586$ billion stimulus package, primarily targeting infrastructure and social welfare projects.

Figure 2. The change in China's economic structure (1995-2017).

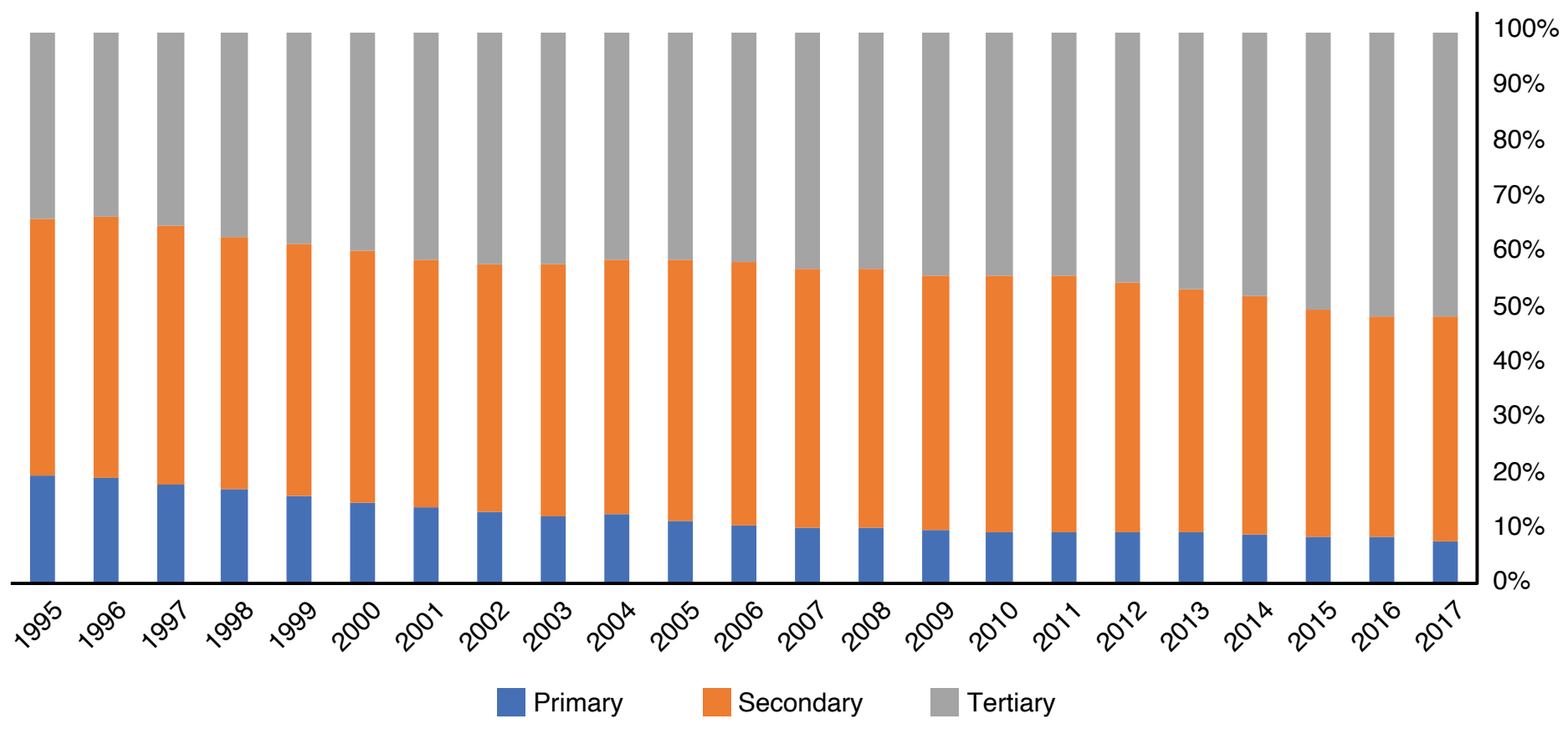

Source: China Statistical Yearbook (2019).

Together, these economic reforms and policy initiatives have had profound impacts on China's economy. China was transformed from a medium-sized developing country into the world's second-largest economy and a global industrial powerhouse. While the size of its economy 
grew exponentially, its structure also underwent considerable changes: the shares of primary and secondary sectors declined and the tertiary sector grew (Figure 2). This significantly changed China's domestic and international freight activities. In light of these economic impacts on freight transport, the next section presents an extended IO framework that captures the interaction between production chain dynamics and freight movement.

\section{Extended input-output (IO) analysis}

The extended IO approach was originally pioneered by Leontief (1970) to investigate the relationship between the economy and environmental issues. In recent years, it has been increasingly adopted by transport researchers to study national and regional freight transport demand, as it can connect production sector interdependencies with freight activities that arise from inter-industry trade flows in the economy (see, e.g., Nealer et al. [2011]; Cascetta et al. [2013]; Alises and Vassallo [2015]; Alises and Vassallo [2016]; Yu [2018]). The model builds on Leontief's basic IO framework, which can be expressed in the following matrix form:

$X=L * f$

where $X(n \times 1)$ indicates the total output of the $n$ sectors of the economy, ${ }^{2} L(n x n)$ is the Leontief inverse matrix that reflects the inter-sectoral production linkages, and $f(n \times l)$ is the final demand vector (Miller and Blair 2009). The basic model is then augmented by multiplying the freight intensity coefficient matrix to connect the overall economic activities with the generated freight movement:

$T=F I * L * f$

$T(m \times 1)$ indicates the quantity of freight activities by $m$ modes of transport, as expressed in tkm. FI $(m \times n)$ is the freight intensity matrix that measures the freight tkm per unit of total output for each combination of the $n$ economic sectors and $m$ transport modes.

McKinnon (2007) focused on road freight intensity, using a similar approach to the one given above to evaluate the relationship between economic activities and road freight. However, it should be noted that the method employed in this paper differs from McKinnon (2007) in two important ways. First, in addition to road vehicles, this paper also accounts for other modes of freight transport, including railway, inland waterway, domestic and international maritime shipping. Second, it measures freight intensity against total output instead of gross domestic product (GDP). GDP only measures the values of final goods and services, while total output also takes the values of intermediate goods and services into account. Since the freight statistics capture the flow of both intermediate and final products, dividing total freight tkm by total output provides a better estimate of freight intensity than dividing tkm by GDP.

Figure 3 offers a conceptual framework to understand the structural drivers of economic growth and the resultant freight movement. The ultimate determinant of the relationship between the economy and freight is a country's level of economic development and income, which in turn determines the main final demand (or end-user) patterns in an economy: consumption (household and government), investment (or capital formation, including gross fixed capital formation and inventory change), and exports. Each of the end users (consumption, investment, exports) consumes a different combination of final goods and services produced by the downstream production sectors. Finally, downstream demand is passed to the 
upstream sectors, which produce raw materials, energy, semi-finished goods and other intermediate inputs for downstream production. The flow of goods between upstream sectors, downstream sectors and end users forms the observed freight movement.

Figure 3. The relationship between economic development and freight transport demand.

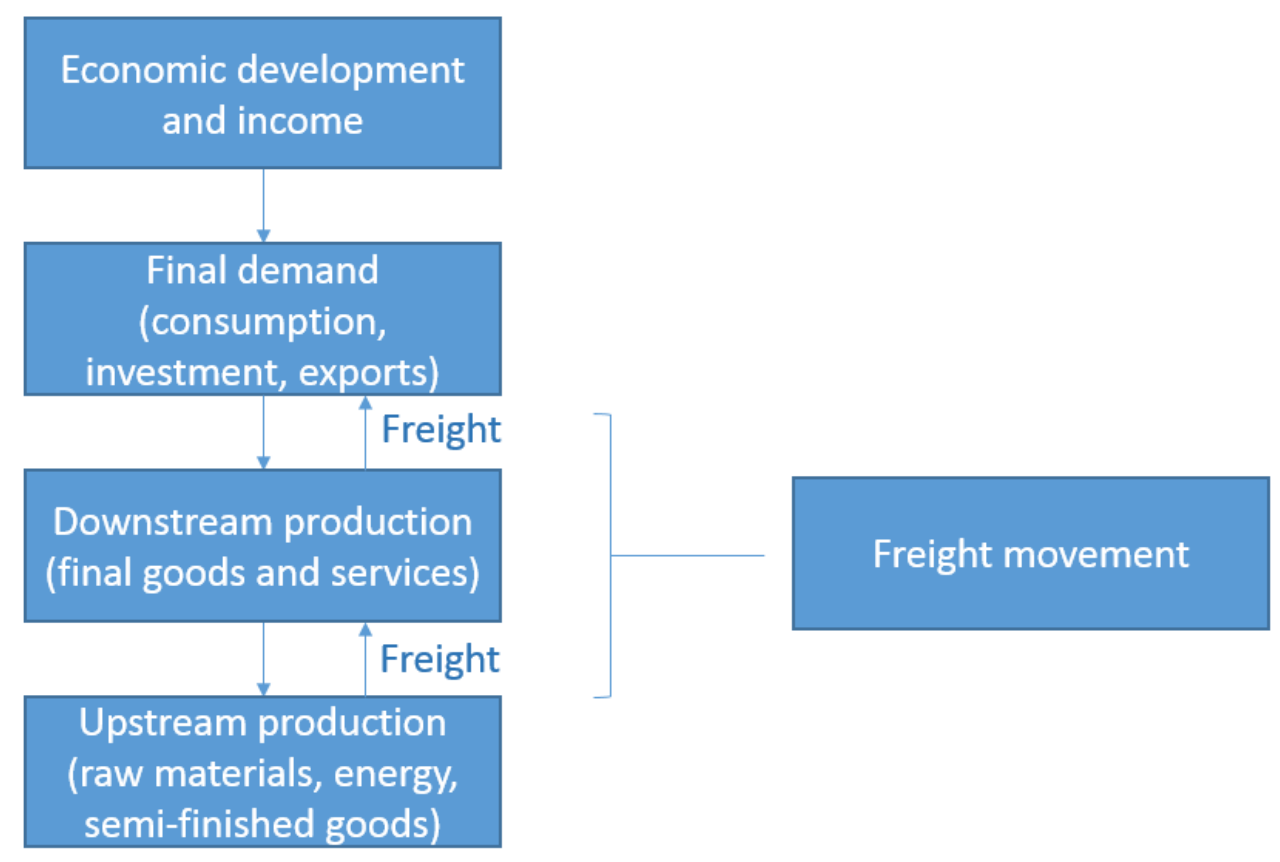

Within the input-output framework, the structural changes in the economy can be driven by changes in both the economic/production structure and the end users' distribution share. Downstream sectors that produce final goods and services directly consumed by the three end-user categories of the economy are the main drivers of economic and freight activities. Since freight statistics do not differentiate between 'direct' freight transport of the final output of downstream production and the 'indirect' freight transport required by the upstream supply chain, it is important to utilize the input-output method to obtain a lifecycle view of freight movement in the supply-production-consumption process. This can help reorient the freight statistics in order to reflect the real freight transport demand of the economy's main sectoral drivers.

In this respect, the quantitative impact of each downstream sector's demand on its supply chain can be evaluated using the following equation:

$X_{\text {sector }}=L * \operatorname{diag}(f)$

where $\operatorname{diag}(f)$ is the $n x n$ diagonalized form of the vector $f$, and $X_{\text {sector }}(n \times n)$ is a matrix where column $i$ measures the resource input in order to meet the final demand in downstream sector i. $X_{\text {sector }}$ can then be multiplied by the freight transport intensity coefficients to compute total freight demand for various transport modes due to the final demand of a particular production sector. 
Moreover, the pattern of downstream production is further determined by the distribution share of the main final demands in the economy, each consuming a different bundle of final goods and services. For example, as will be shown later in the paper, the main components of the consumption bundle are "consumable goods" and "other services," whereas the largest components of the investment bundle are "construction" and "machinery, electrical and transport equipment." Therefore, it is important to investigate the impact of the evolving final demand structure on freight transport demand further. In this study, the final demand vector $f$ is decomposed into five main end-user components, in line with the available input-output data published by the Chinese statistical authorities: rural household consumption $\left(f_{\text {rural }}\right)$, urban household consumption $\left(f_{\text {urban }}\right)$, government consumption $\left(f_{\text {government }}\right)$, capital formation $\left(f_{\text {capital }}\right)$, and export $\left(f_{\text {export }}\right)$. The model takes the following form:

$T=F I * L *\left(f_{\text {rural }}+f_{\text {urban }}+f_{\text {government }}+f_{\text {capital }}+\right.$ $\left.f_{\text {export }}\right)=T_{\text {rural }}+T_{\text {urban }}+T_{\text {government }}+T_{\text {capital }}+T_{\text {export }}$

where $T_{\text {private }}, T_{\text {urban }}, T_{\text {government }}, T_{\text {capital }}$, and $T_{\text {export }}$ represent the total freight movement arising from the final demand of rural household consumption, urban household consumption, government consumption, capital formation, and exports, respectively.

\section{Structural decomposition analysis}

In practice, materialized freight movement is not only determined by economic demand, but also by supply-side factors such as the availability and competitiveness of various freight transport modes. Hence, the structural decomposition analysis (SDA) technique is applied to investigate the roles of individual drivers of period-to-period freight transport growth in-depth. The SDA approach has been widely applied in environmental research to examine the driving forces of the change in a particular variable over time (for example, for its use in analyzing carbon emissions, see Xu et al. [2011]; Su and Ang [2012]; Su et al. [2017]). It has lately also received increased attention from freight transport researchers (see Alises and Vassallo [2015, 2016]).

In the current formulation, total freight movement can be further modeled as the product of the following five determinants:

sectoral freight transport intensity $F I_{\text {total }}(n \times 1)$, which is computed as total freight movement for all modes divided by the total output for each economic sector; ${ }^{3}$

transport modal mix by sector $F I_{\text {share }}(m \times n)$, which measures the structure of freight transport modes for each economic sector;

production linkages $L$, which is the Leontief inverse matrix that measures the interdependencies between economic sectors;

production structure $f_{\text {share }}(n \times 1)$, which indicates the distribution of production/ economic sectors in the economy;

level of total final demand $f_{\text {total }}(1 \times 1)$, which is equivalent to GDP plus imports. ${ }^{4}$

Therefore, equation (2) can be rewritten as follows:

$$
T=F I_{\text {share }} * \operatorname{diag}\left(F I_{\text {total }}\right) * L * f_{\text {share }} * f_{\text {total }}
$$

where $F I=* F I_{\text {share }} * \operatorname{diag}\left(F I_{\text {total }}\right)$, and $f=f_{\text {share }} * f_{\text {total }}$. 
As indicated previously, the production structure can be further expressed as the product of two factors: the distribution of final demands in the economy $f_{F D}(5 \times 1)$, and the final demand product $\operatorname{mix} f_{\text {product }}(n \times 5)$, which measures the distribution of expenditure across production sectors for each final demand (Miller and Blair 2009), so that

$f_{\text {share }}=f_{\text {product }} * f_{F D}$

As a consequence, total freight movement becomes a product of six variables: transport modal mix, sectoral freight intensity, inter-sectoral production linkages, final demand distribution, final demand product mix, and the level of final demand, as expressed in the following equation:

$$
T=F I_{\text {share }} * \operatorname{diag}\left(F I_{\text {total }}\right) * L * f_{\text {product }} * f_{F D} * f_{\text {total }}
$$

The SDA approach stipulates that the change in $T$ from time 0 to time 1 can be attributed to contributions from changes in all six determinants:

$$
\begin{aligned}
& \Delta T^{0-1} \\
& =\underbrace{\left(\frac{1}{2}\right) \Delta F I_{\text {share }}{ }^{0-1}\left[\operatorname{diag}\left(F I_{\text {total }}\right)^{0} * L^{0} * f_{\text {product }}{ }^{0} * f_{F D}{ }^{0} * f_{\text {total }}{ }^{0}+\operatorname{diag}\left(F I_{\text {total }}\right)^{1} * L^{1} * f_{\text {product }}{ }^{1} * f_{F D}{ }^{1} * f_{\text {total }}{ }^{1}\right]} \\
& + \\
& \underbrace{\left(\frac{1}{2}\right)\left[F I_{\text {share }}{ }^{0-1} * \Delta \operatorname{diag}\left(F I_{\text {total }}\right)^{0-1} * L^{0} * f_{\text {product }}{ }^{0} * f_{F D}{ }^{0} * f_{\text {total }}{ }^{0}+\Delta \operatorname{diag}\left(F I_{\text {total }}\right)^{0-1} * L^{1} * f_{\text {product }}{ }^{1} * f_{F D}{ }^{1} * f_{\text {total }}{ }^{1}\right]} \\
& + \\
& \underbrace{\left(\frac{1}{2}\right)\left[F I_{\text {share }}{ }^{0-1} * \operatorname{diag}\left(F I_{\text {total }}\right)^{0} * \Delta L^{0-1} * f_{\text {product }}{ }^{0} * f_{F D}{ }^{0} * f_{\text {total }}{ }^{0}+\operatorname{diag}\left(F I_{\text {total }}\right)^{1} * \Delta L^{0-1} * f_{\text {product }}{ }^{1} * f_{F D}{ }^{1} * f_{\text {total }}{ }^{1}\right]}_{\text {production linkage change effect }} \\
& + \\
& \underbrace{\left(\frac{1}{2}\right)\left[F I_{\text {share }}{ }^{0-1} * \operatorname{diag}\left(F I_{\text {total }}\right)^{0} * L^{0} * \Delta f_{\text {product }}{ }^{0-1} * f_{F D}{ }^{0} * f_{\text {total }}{ }^{0}+\operatorname{diag}\left(F I_{\text {total }}\right)^{1} * L^{1} * \Delta f_{\text {product }}{ }^{0-1} * f_{F D}{ }^{1} * f_{\text {total }}{ }^{1}\right]} \\
& + \\
& \underbrace{\left(\frac{1}{2}\right)\left[F I_{\text {share }}{ }^{0-1} * \operatorname{diag}\left(F I_{\text {total }}\right)^{0} * L^{0} * f_{\text {product }}{ }^{0} * \Delta{f_{F D}}^{0-1} * f_{\text {total }}{ }^{0}+\operatorname{diag}\left(F I_{\text {total }}\right)^{1} * L^{1} * f_{\text {product }}{ }^{1} * \Delta f_{F D}{ }^{0-1} * f_{\text {total }}{ }^{1}\right]} \\
& + \\
& \underbrace{\left(\frac{1}{2}\right)\left[F I_{\text {share }}{ }^{0-1} * \operatorname{diag}\left(F I_{\text {total }}\right)^{0} * L^{0} * f_{\text {product }}{ }^{0} * f_{F D}{ }^{0}+\operatorname{diag}\left(F I_{\text {total }}\right)^{1} * L^{1} * f_{\text {product }}{ }^{1} * f_{F D}{ }^{1}\right] \Delta f_{\text {total }}{ }^{0-1}}_{\text {final demand growth effect }}
\end{aligned}
$$

where "0" and "1" indicate time 0 and time 1, respectively, and $\Delta$ and "0-1" indicate the variation of the variable between periods. In other words, the change in total freight movement is the summation of effects of the six driving factors:

changes in freight transport modal structure for each economic sector; changes in sectoral freight intensity;

changes in production interdependencies across economic sectors; 
changes in the distribution of the economy's final demands, i.e., household and government consumption, investment/capital formation, and exports;

changes in the product expenditure of each final demand/end user;

changes in the level of final demand.

Among the six determinants, the effects of the economic structural changes are primarily reflected by the evolution of the final demand structure and the end users' product expenditure patterns.

Following Alises and Vassallo (2016), the detailed decomposition of freight movement growth into individual components also enables scenario analysis. This can simulate the separate impact of the changes of each component, whether resulting from policy intervention or changes in the economy. Section 5 discusses the results of the simulation analysis and their implications for policymakers.

\section{Data and assumptions}

Both economic input-output and freight transport data are needed to relate the information on economic production to freight transport. As noted in figures 1 and 2, over the last decades China's economy has not only expanded substantially, it has also changed considerably in its composition, steadily transitioning and upgrading its production structure. As a result, the country has gradually moved up the global value chain from being an exporter of primary natural resource commodities and low value-added consumable goods to becoming one of the largest buyers of raw materials and producers of finished goods. Recently, China announced a series of major policy initiatives to further promote its domestic industrial upgrade, including Made in China 2025 and the Belt and Road Initiative. These policies will prioritize the development of high value-added manufacturing and service industries, whereas low value-added and oversupplied economic sectors are expected to be relocated and outsourced.

To reflect these ongoing structural changes in the Chinese economy and to analyze their impact on freight transport demand, we group economic and freight data into eight commodity sectors. The main reason for this broad categorization is to differentiate the economic sectors that have played a dominant role in fueling China's economic growth in the past from those that are more sensitive to the ongoing industrial upgrade.

\section{Consumable goods}

Included sectors: agriculture, forestry and fishing products; wood and wood products; food, beverages and tobacco; textiles and textile products; leather and footwear; paper, printing and publishing products; toys, art and sports goods; medicine

\section{Bulk commodities}

Included sectors: mining and quarrying; coke and refined petroleum; other non-metallic minerals; basic metals, fabricated metal and metal products

\section{Chemical products}

Included sectors: chemicals and chemical products; fertilizers and pesticides; rubber and plastics 
Machinery, electrical and transport equipment

Included sectors: machinery and equipment; electrical and optical equipment; electronic products; motor vehicles and other transport equipment

\section{Utilities}

Included sectors: suppliers of electricity, gas, and hot water; water suppliers

\section{Construction}

Included sectors: construction and buildings; civil engineering

\section{Transport services}

Included sectors: railway passenger and freight transport; road passenger and freight transport; urban public transport; waterway passenger and freight transport; air passenger and freight transport; pipeline transport; auxiliary transport activities

\section{Other services}

Included sectors: post and telecommunications; retail and wholesale trade; hotels and restaurants; real estate and financial activities; public administration and defense; education and health services; media and entertainment; community and social services; sports; social work and social welfare; science and research; computer programming, software and internet; tourism; rental and other business services; management of the environment and public facilities

Based on this categorization, both the input-output and the freight transport data are aggregated accordingly. The highest level of detail is necessary to facilitate a comparison and homogenization. For this reason, detailed input-output data published by China's National Bureau of Statistics every five years from 1997 to 2017 are used. At a high-resolution level, the $\mathrm{IO}$ data can be aggregated into the eight sectors listed above. Figure 4 illustrates the transition of China's industrial structure from 1997-2017 based on data from the IO tables. The left-hand side of the figure displays the share of value added from goods-producing sectors (consumable goods, bulk commodities, chemical products, and machinery, among others), and the right-hand side of the figure shows the share from non-goods-producing sectors (utility, construction, ${ }^{5}$ transport services, and other services). It is evident from the figure that while the Chinese economy is the world's second largest, its focus is gradually moving toward high-value manufacturing and service activities: the share of the consumable goods sector is declining, and those of higher value-added activities, such as machinery, electrical and transport and other services are steadily increasing.

Data on the following five freight transport modes are used: road, railway, domestic inland waterway shipping, domestic coastal shipping, and international maritime shipping. Unlike the IO data, China's freight transport statistics across different modes are not reported consistently, nor presented at the same level of detail. Therefore, several assumptions are made to map the freight data to the desired sector classification. Details on the sources and treatment of both the $\mathrm{IO}$ and freight data are available in the appendix. 
Figure 4. Shares of the goods-producing and non-goods-producing sectors in China's value added, 1997-2017.

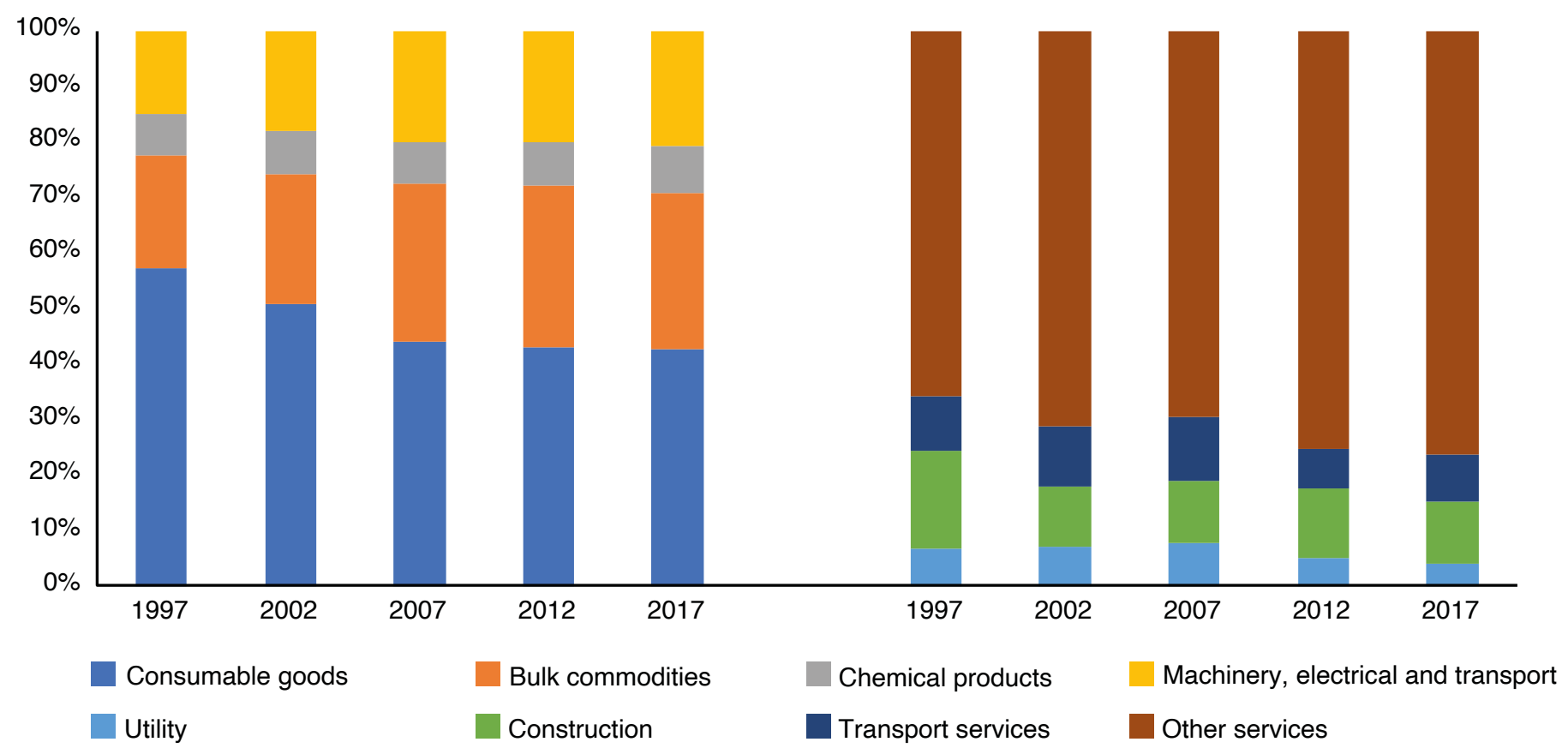

Source: National Bureau of Statistics (2019), and authors' calculations.

Figure 5 illustrates the observed freight movement in China, organized by commodity sectors and transport modes for 1997-2012. ${ }^{6}$ Note that, by definition, all freight cargo is generated by the goods-producing sectors (consumable goods, bulk commodities, chemical products, and machinery, electrical and transport). Hence the non-goods-producing sectors (utility, construction, transport services, other services) are excluded.

China's freight transport has grown rapidly since 1997, especially following its entry into the WTO in 2001. Bulk commodities occupy the largest share of its cargo, followed by consumable goods. Machinery, electrical and transport initially occupied the smallest share, but in 2007 it surpassed chemical products as the third-largest category. Rail was the primary mode of domestic freight transport between 1997 and 2007, accounting for the majority of most sectors' domestic tkm. However, with the remarkable growth of road freight, the share of rail freight transport had decreased substantially by 2012. ${ }^{7}$ Low-value cargo (as measured against its weight) such as bulk commodities (e.g., coal, iron ore, etc.) tend to be transported mostly by rail and waterways. In contrast, high-value goods such as machinery and electrical equipment, and goods with fast delivery requirements (e.g., perishable food in the consumable goods sector) are more likely to be transported by road. 
Figure 5. China's observed freight movement (tkm) by aggregate commodity type and transport modes, 1997-2012.

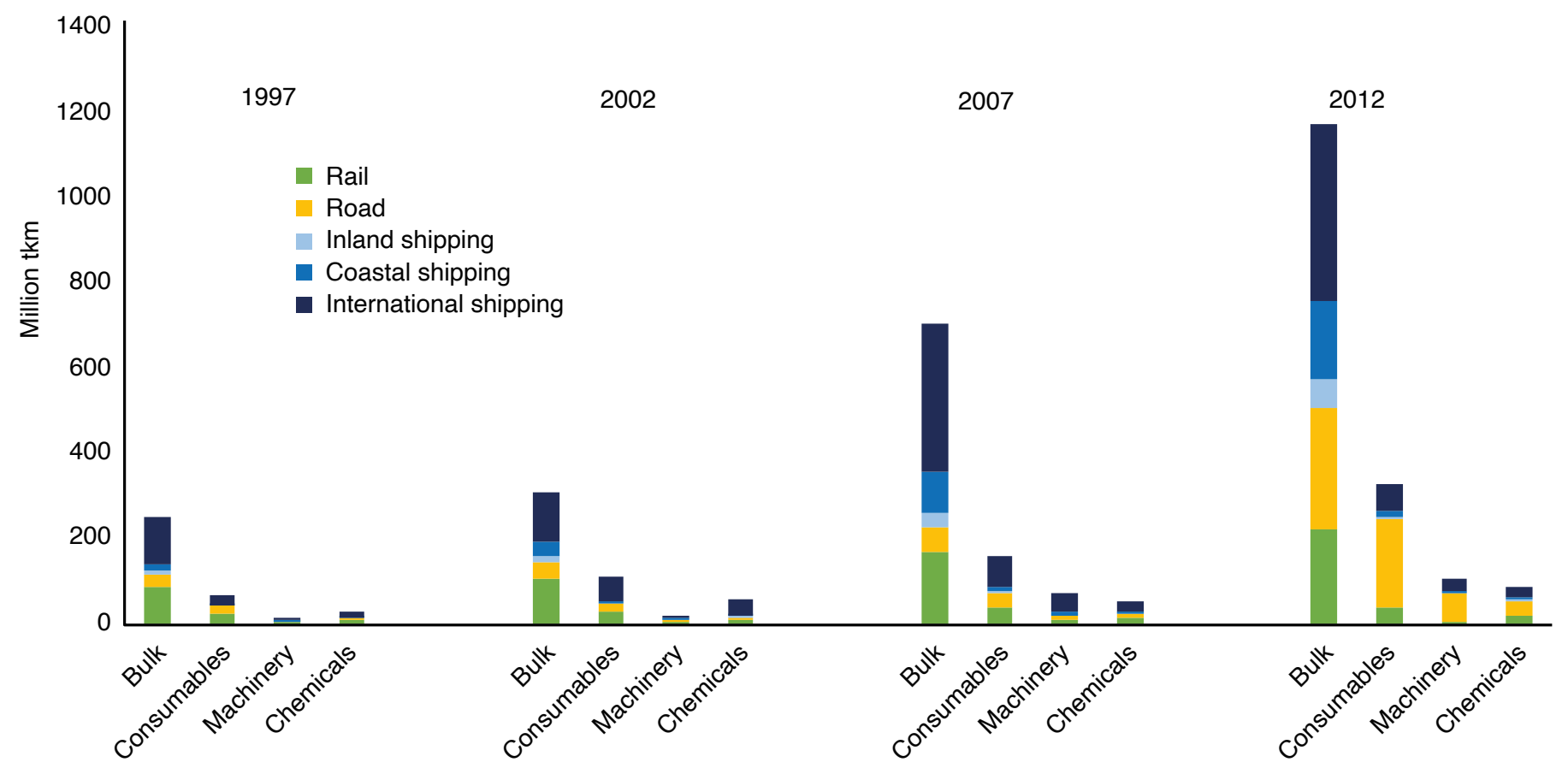

Source: Authors' calculations. 


\section{Key Drivers of Freight Transport Growth}

igure 6 presents the results of the extended IO analysis. It shows the total embodied freight movements of the eight downstream economic sectors. In contrast to Figure 5, which shows the observed freight movement by commodity type, Figure 6 reveals the downstream sectors that generate the demand for the movement of these commodities in the supply chain. These include both goods-producing and non-goods-producing sectors.

Figure 6. Embodied total freight movement by economic sector and transport modes, 1997-2012.

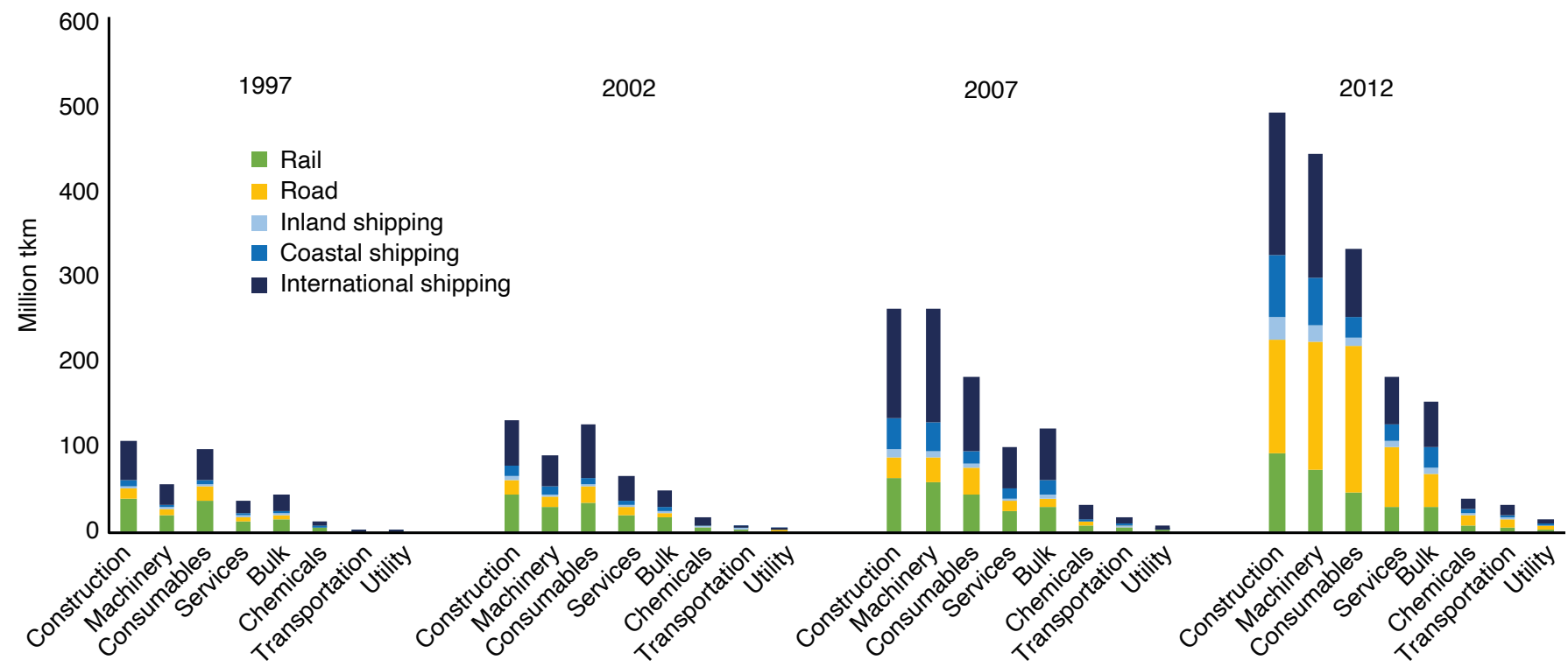

Source: Authors' calculations.

A comparison of the two figures yields several interesting observations. First, although bulk commodities is the most prominent commodity category in observed freight movement, as a downstream sector it generates much less demand for freight. This suggests that bulk cargoes are primarily used for production output by other sectors of the economy. Second, compared to the goods-producing sectors, the non-goods-producing sectors had significant requirements for freight transport in their supply chains. Their share of total embodied freight movement averaged 42\% during 1997-2012. Of all eight economic sectors, construction has consistently been the largest source of freight transport demand. This has been likely driven by China's property market boom, its massive infrastructure development and the extraordinary growth of other construction activities throughout the period considered. Another noteworthy point is the structural change in China's economy, illustrated by the dynamics of its embodied freight movement. While the economy was initially skewed toward the production of consumable goods, it is now transitioning toward a high-value manufacturing-focused industrial structure. The machinery, electrical and transport equipment sector has surpassed the consumable goods sector to become the second largest source of embodied freight movement. 


\section{Key Drivers of Freight Transport Growth}

Figure 7. Embodied freight transport from the end users' perspective, 1997-2012.

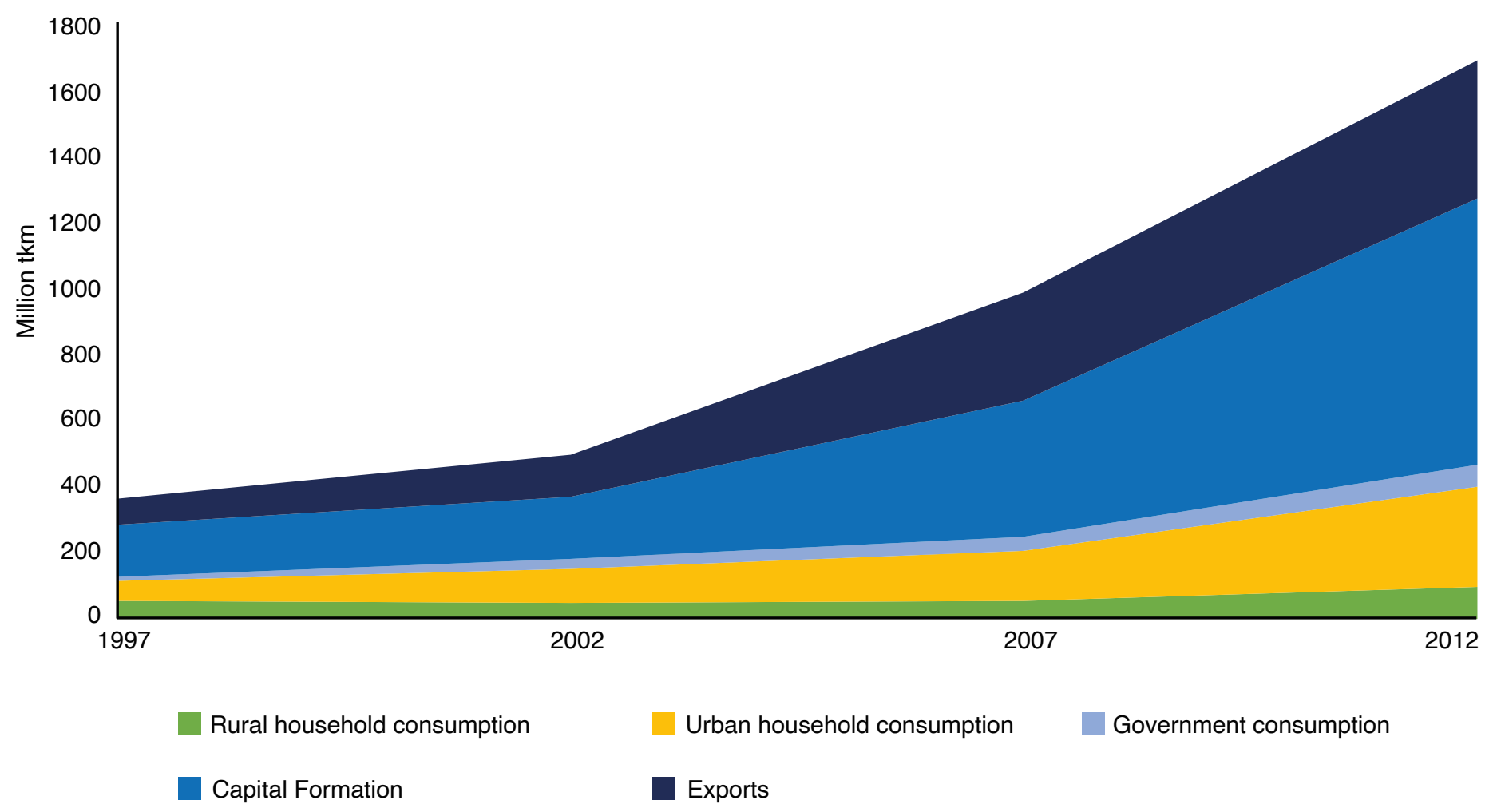

Source: Authors' calculations.

Figure 7 shows the end-user demand for freight transport. As mentioned in section 2, five end-user categories are distinguished: rural household consumption, urban household consumption, government consumption, capital formation (which equals gross fixed capital formation plus inventory changes), and exports.

Between 1997 and 2012, the most notable change was the fast-rising demand for freight from capital formation. The share of freight movement from capital formation rose from $43 \%$ in 1997 to about $48 \%$ in 2012, suggesting that investment activities were the predominant sources of freight transport demand during this period. Freight movement from exports also grew quickly between 2002 and 2007.
Although exports' rate of growth lessened after the 2008 global financial crisis, they still accounted for a quarter of total freight movement in 2012, as they represent demand from foreign customers. In contrast, the share of freight activities generated by all consumption dropped from $36 \%$ to $28 \%$ between 1997 and 2012. Freight transport demand from urban household and government consumption has largely kept pace with the growth of overall freight movement, whereas the share of freight for rural household consumption dropped from 15\% in 1997 to only $6 \%$ in 2012 . While this is partially due to China's fast urbanization and the resultant reduction in the share of its rural population, it also reflects the relatively slow growth of household consumption in the rural region during this period. 
Table 1 presents a further breakdown of end-user freight transport demand, showing the three production sectors with the largest embodied freight movement per end user. ${ }^{8}$ As expected, the product expenditure pattern differs greatly among end users. The sectors generating the highest urban and rural household freight transport demand are consumable goods and other services. Construction and machinery, electrical and transport generated the highest freight movement from capital formation. This demand was reflected in the massive investment in buildings, equipment and infrastructure in both the private and the public sectors in China from 1997-2012. From 2002, machinery, electrical and transport replaced bulk commodities as the largest user of embodied freight transport for exports. This suggests that China was starting to transform from being an exporter of raw materials and other primary resources to an exporter of finished products, most notably electric and electronic products, and machinery, electrical and transport products.

Table 1. Shares of embodied freight transport by final demand and production sector, 1997-2012.

\begin{tabular}{|c|c|c|c|c|c|c|c|c|c|c|c|}
\hline \multicolumn{3}{|l|}{1997} & \multicolumn{3}{|l|}{2002} & \multicolumn{3}{|l|}{2007} & \multicolumn{3}{|l|}{2012} \\
\hline Capital & Construction & $30 \%$ & Capital & Construction & $27 \%$ & Capital & Construction & $26 \%$ & Capital & Construction & $29 \%$ \\
\hline & Machinery & $8 \%$ & & Machinery & $9 \%$ & & Machinery & $12 \%$ & & Machinery & $13 \%$ \\
\hline & Consumables & $2 \%$ & & Consumables & $1 \%$ & & Bulk & $2 \%$ & & Consumables & $2 \%$ \\
\hline Export & Bulk & $7 \%$ & Export & Machinery & $7 \%$ & Export & Machinery & $13 \%$ & Export & Machinery & $10 \%$ \\
\hline & Consumables & $5 \%$ & & Consumables & $7 \%$ & & Bulk & $9 \%$ & & Bulk & $6 \%$ \\
\hline & Machinery & $5 \%$ & & Bulk & $6 \%$ & & Consumables & $6 \%$ & & Consumables & $5 \%$ \\
\hline Ub. HH & Consumables & $9 \%$ & Ub. HH & Consumables & $11 \%$ & Ub. HH & Consumables & $7 \%$ & Ub. HH & Consumables & $9 \%$ \\
\hline & Services & $2 \%$ & & Services & $4 \%$ & & Services & $4 \%$ & & Service & $4 \%$ \\
\hline & Bulk & $2 \%$ & & Bulk & $2 \%$ & & Machinery & $2 \%$ & & Machinery & $2 \%$ \\
\hline Rr. HH & Consumables & $10 \%$ & Rr. HH & Consumables & $6 \%$ & Rr. HH & Consumables & $3 \%$ & Rr. HH & Consumables & $4 \%$ \\
\hline & Services & $2 \%$ & & Services & $2 \%$ & & Services & $1 \%$ & & Services & $1 \%$ \\
\hline & Bulk & $1 \%$ & & Bulk & $1 \%$ & & Machinery & $0 \%$ & & Machinery & $0 \%$ \\
\hline
\end{tabular}

Source: Authors' calculations.

Note: Ub. $\mathrm{HH}=$ urban households; $\mathrm{Rr}$. $\mathrm{HH}=$ rural households. 


\section{The Structural Decomposition Analysis}

$\mathrm{n}$ practice, materialized freight movement is not only determined by the quantity of goods transported and the distances traveled, it is also affected by conditions related to the supply of freight transport services, which offers potential room for policy intervention. For example, optimizing the transport modal structure via, for instance, enlarging the share of rail freight and waterway shipping, could be an important vehicle for reaching objectives such as energy conservation and carbon emissions mitigation. Likewise, reducing freight intensity provides another useful means of achieving these goals. This section discusses the result of the period-to-period structural decomposition analysis, which delineates the separate impact of the six determinants: the sectoral freight transport intensity, the modal split, the production linkages of the supply chain, the distribution share of end users, the product expenditure pattern of end users, and the level of total final demand.

Freight intensity is an important determinant of total freight transport because greater freight intensity will lead to more freight activities, given the same total output. Figure 8 shows the sectoral freight transport intensity for the observed freight movement. A clear downward trend can be seen over time. Among the four sectors, bulk commodities have the highest freight intensity, most probably due to the high weight-to-value ratio and the long distances that many raw materials and primary commodities travel to China. In contrast, machinery, electrical and transport has the lowest intensity, likely because this sector's products have much higher per unit weight values. The notable decline of freight intensity in some sectors, especially bulk commodities, is partly due to rapidly rising international commodity prices during the 2000s as a result of China's strong demand for these products (Roberts et al. 2016).
This increases the value of the denominator and reduces the value of the intensity. Another possible explanation for the overall intensity decline could be the spatial optimization of production centers and supply locations, resulting in a reduction in average distances needing to be traveled.

Figure 9 further shows the intensity of embodied freight movement for all downstream sectors. While the bulk commodities sector still has the highest freight intensity, the variation of intensity levels among most of the other sectors is small and has been decreasing over time. The services sector displays a much lower level of intensity than all other sectors because it has a relatively short supply chain and requires much less material input. In this regard, the continuing expansion of the less freight-intensive tertiary industries may impose significantly negative effects on China's overall freight transport demand in the future.

Figure 10 presents the freight transport dynamics for the four commodity sectors. One of the most important modal structural changes is the steady decline in the use of rail transport, traditionally the primary domestic means of long haul shipping for bulk cargo (e.g., coal, iron ore, etc.). As China's participation in the global commodity market grows, its demand for bulk commodities is increasingly met by imports and is less reliant on domestic supply. This leads to the partial substitution of domestic railway freight transport by international maritime shipping (Wang 2015). The share of road freight in China to transport commodities grew significantly after 2007. While this was in part thanks to the swift improvement of the country's highway infrastructure (Blancas et al. 2015), it also reflects the growing competitiveness of China's trucking sector relative to other domestic freight transport modes. 
Figure 8. Sectoral freight transport intensity of observed freight movement, 1997-2012.

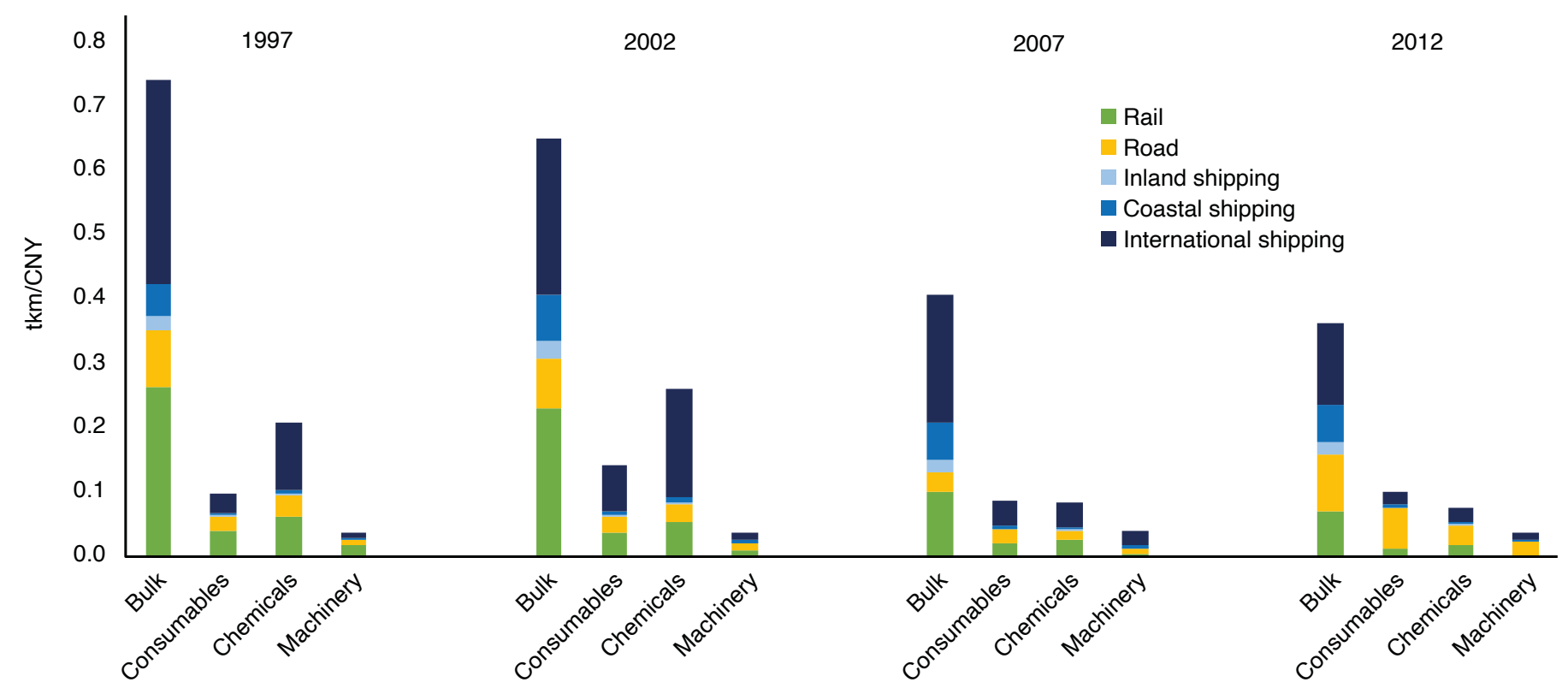

Source: Authors' calculations.

Note: $\mathrm{CNY}=$ Chinese renminbi.

Figure 9. Sectoral freight transport intensity of embodied freight movement, 1997-2012.

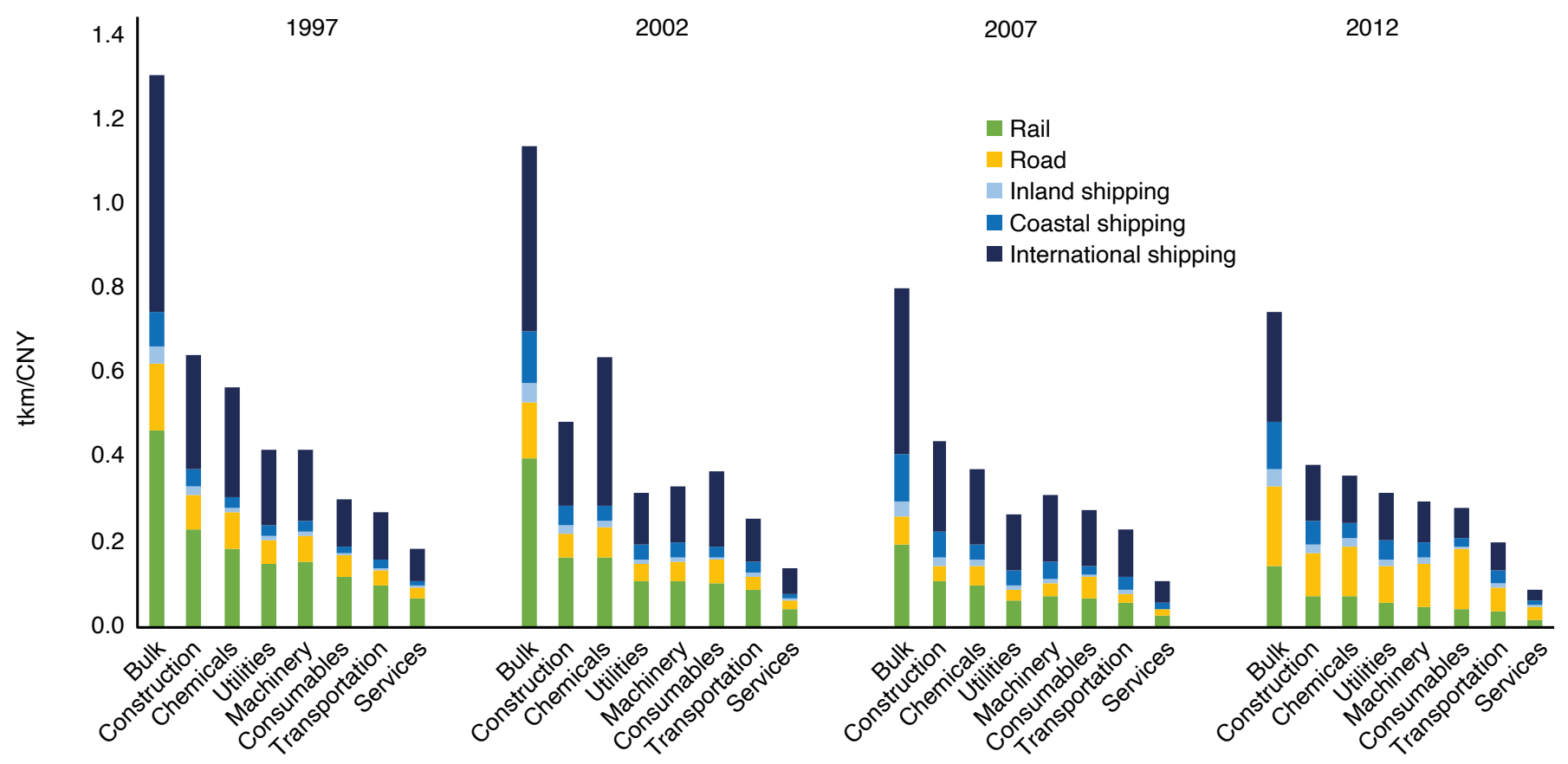

Source: Authors' calculations.

Note: $\mathrm{CNY}=$ Chinese renminbi. 
Figure 10. Actual (1997-2012) and assumed (2017-2020) transport modal split for goods-producing sectors.

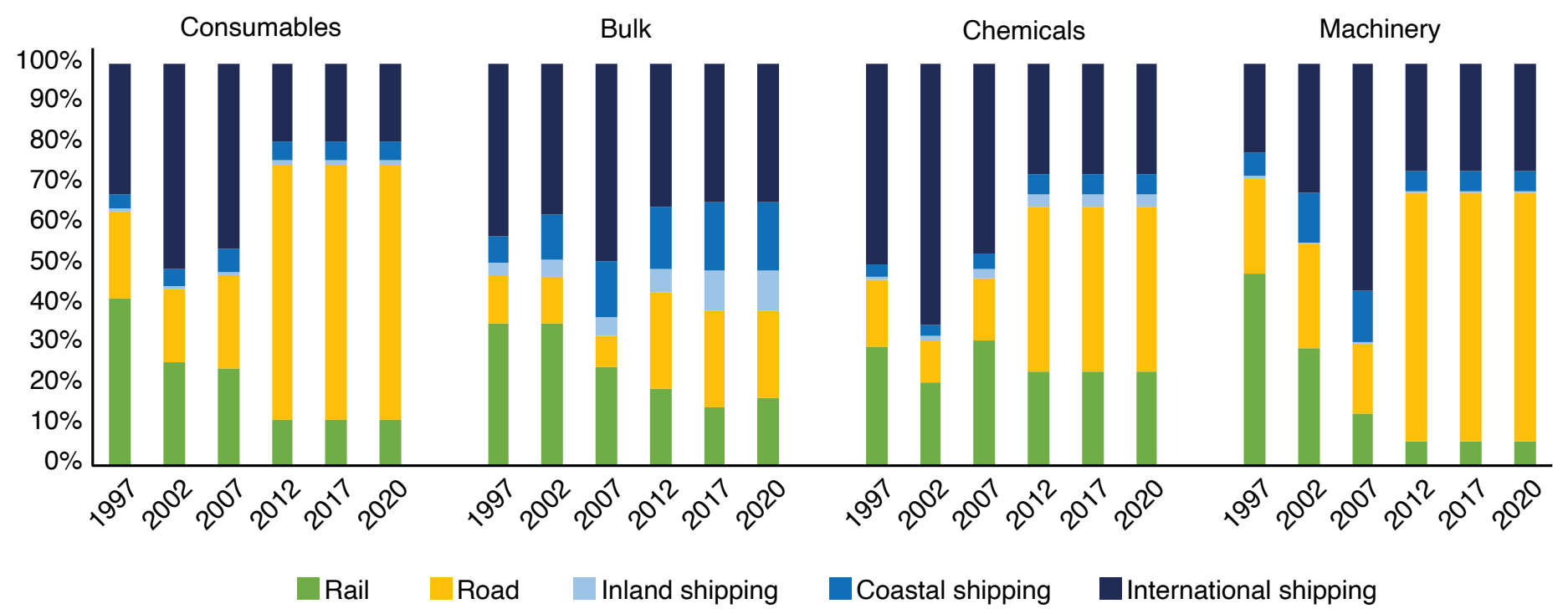

Source: Authors' calculations.

Table 2 shows China's final demand distribution, and Figure 11 shows the country's product expenditure pattern. Between 1997 and 2012, nearly all final demand components' share grew, except for rural household consumption. Capital formation and exports, combined, witnessed the largest gain, rising to almost $60 \%$ of total final demand in 2012. In contrast, the share of rural household consumption shrank to $7 \%$, less than one-third of urban household consumption. Consequently, total household consumption dropped significantly, from $40 \%$ in 1997 to $30 \%$ in 2012 . Meanwhile, notable changes took place in end users' product expenditure patterns. For example, household expenditure on services steadily increased, while expenditure on consumable goods dropped. Rural households lagged behind their urban counterparts in services consumption. Capital formation also spent an increasing amount on services, albeit at a much slower pace than households. Machinery, electrical and transport equipment quickly overtook consumable goods and bulk commodities, combined, as the largest export item.

Changes in both end-user distribution and their product expenditure pattern yield the evolution of the economy's overall production structure (Figure 12). Similar to the findings in Figure 4, the largest development over time is the growth in the services and the machinery, electrical and transport sectors, primarily due to their increased consumption by the economy's main end users. 
Table 2. Actual (1997-2017) and assumed (2020) structure of final demand.

\begin{tabular}{l|c|c|c|c|c|c} 
& $\mathbf{1 9 9 7}$ & $\mathbf{2 0 0 2}$ & $\mathbf{2 0 0 7}$ & $\mathbf{2 0 1 2}$ & $\mathbf{2 0 1 7}$ & $\mathbf{2 0 2 0}$ \\
\hline Rural HH consumption & $20 \%$ & $11 \%$ & $7 \%$ & $7 \%$ & $7 \%$ & $7 \%$ \\
\hline Urban HH consumption & $20 \%$ & $24 \%$ & $21 \%$ & $23 \%$ & $26 \%$ & $30 \%$ \\
\hline Gov. consumption & $10 \%$ & $13 \%$ & $10 \%$ & $11 \%$ & $13 \%$ & $13 \%$ \\
\hline Capital formation & $32 \%$ & $31 \%$ & $33 \%$ & $38 \%$ & $37 \%$ & $37 \%$ \\
\hline Exports & $18 \%$ & $21 \%$ & $28 \%$ & $21 \%$ & $17 \%$ & $13 \%$
\end{tabular}

Source: Authors' calculations.

Note: $\mathrm{HH}=$ household; Gov. = government.

Figure 11. Actual (1997-2017) and assumed (2020) product expenditure pattern by final demand.
Rural HH cons.
Urban $\mathrm{HH}$ cons.
Gov. cons.
Capital formation
Exports

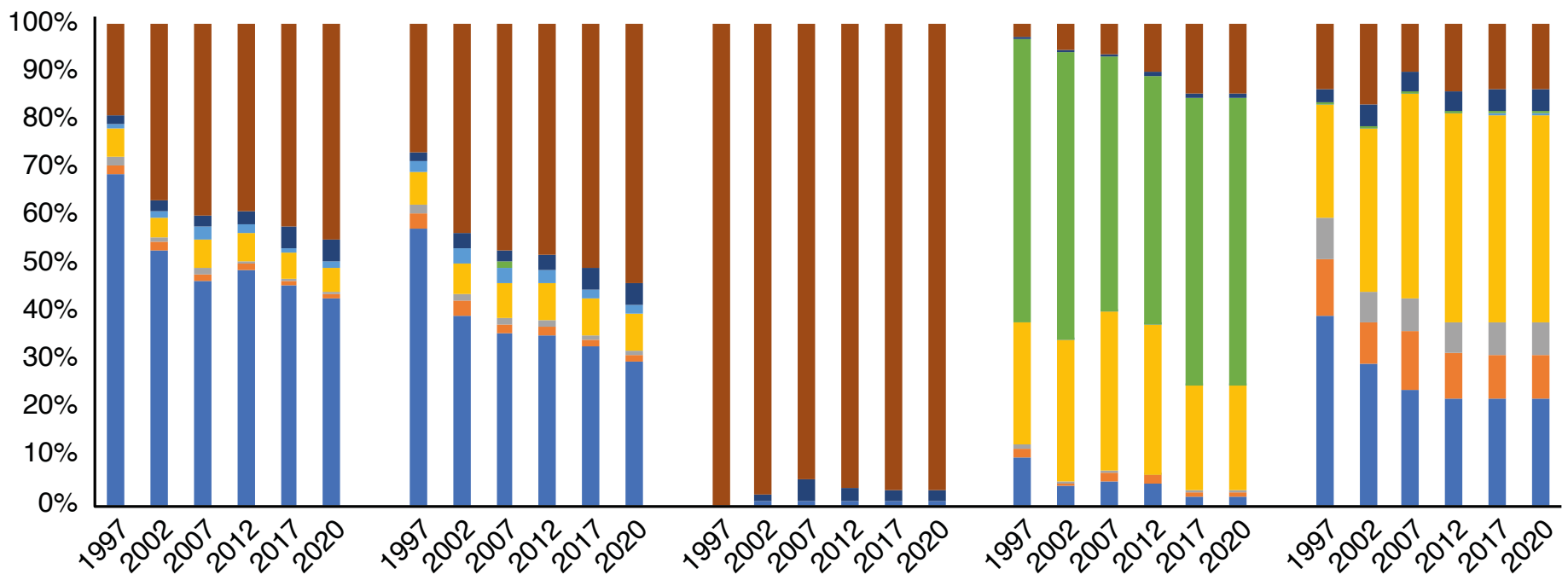

Consumables Bulk Chemicals Machinery Utilities Construction Transportation Services

Source: Authors' calculations.

Note: $\mathrm{HH}=$ household; cons. = consumption; Gov. = government. 
Figure 12. Actual (1997-2017) and assumed (2020) pattern of total final demand expenditures.

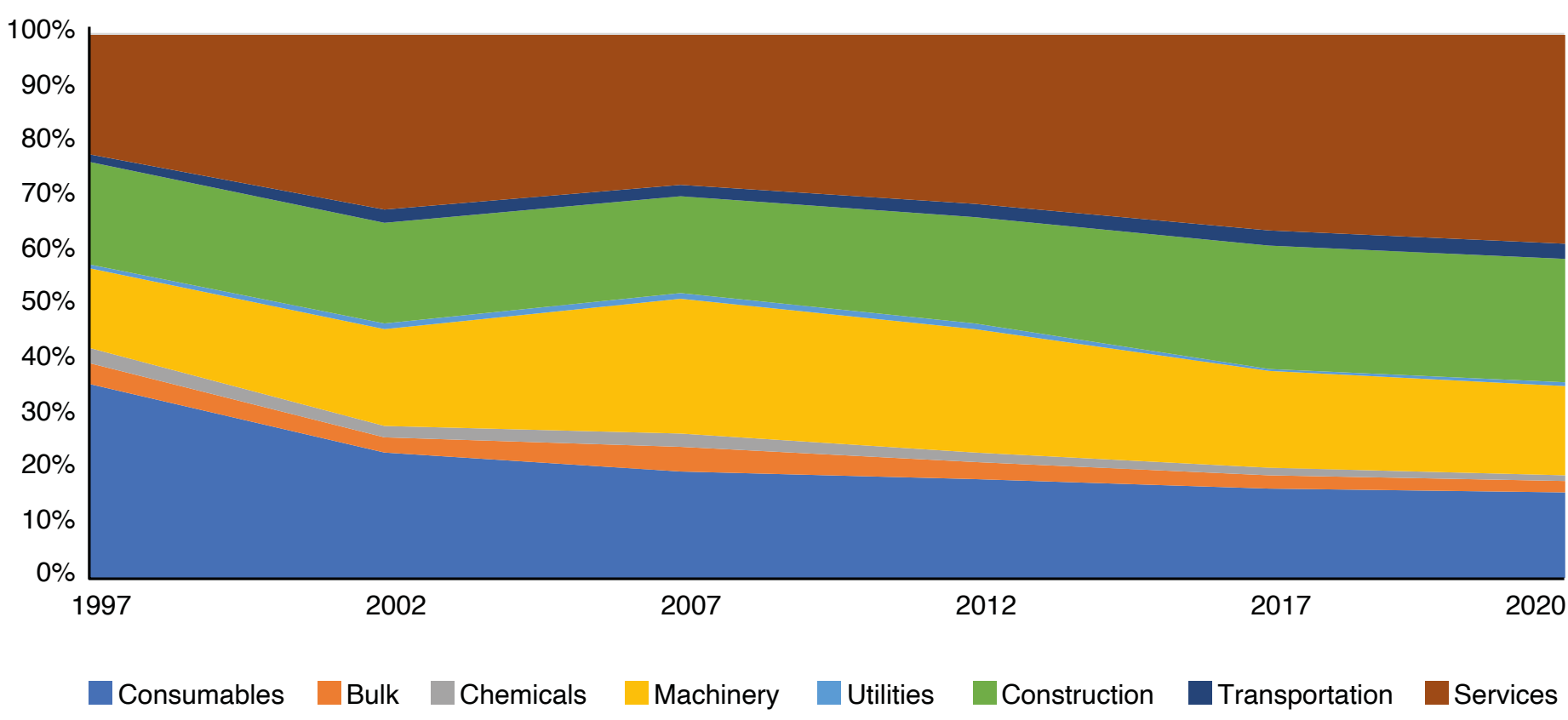

Source: Authors' calculations.

Figure 13 shows the result of the structural decomposition analysis, which measures the cumulative impact of the six determinants on the growth of freight movement between 1997 and 2012 for all five modes. Each colored bar represents the percentage variation of freight volume by a single transport mode compared to the base year due to a particular determinant, and their summation reflects the resulting overall change. To facilitate a visual comparison, 1997 is used as the base year for all the period-to-period calculations.

Among the individual determinants, the growth in final demand, which averaged $15 \%$ per annum from 1997-2012, was the largest positive contributor to freight activity growth. Production linkages also show a positive effect on all modes, especially after 2002. This was likely due to the lengthening and increasing sophistication of the economy's supply chain, following China's entry into the WTO. On the other hand, the reduction in sectoral freight intensity was the largest negative contributor to freight transport growth, probably due to a combination of improvements in logistical efficiencies and the rising commodity prices mentioned previously. The modal structural changes were mixed: the 15-year period reveals a trend of substitution of railway freight transport by other modes such as road, inland and coastal shipping.

The effects of the structural change in final demand and the change in product expenditure patterns were moderate but seem small relative to other contributing factors. This is in part due to the much smaller changes in these variables compared to other variables during the period. Also noteworthy is the opposite effects final demand and product expenditure patterns seem to have had in most cases. Final demand structural changes had positive effects on freight movement most of the time, suggesting the increasing influence of the more freight-intensive end users (such as capital 
formation) during this period. Meanwhile, the negative effect of changes in product expenditure patterns on freight movement shows a trend toward reduced freight intensiveness in the product mix for each end user's demand. This is indicated by the growing share of the services sector in Figure 11. The combined net effect was mixed across modes between 1997 and 2012: it was positive for inland and coastal waterway shipping, and negative for rail, road trucking, and international maritime shipping.
Overall, the two economic structural variables, final demand and product expenditure patterns, had opposite and notable impacts. Their impact on aggregate freight transport demand, however, was outweighed by the change in total final demand, which saw unprecedented growth during this period.

Figure 13. The impacts of various contributing factors on the growth of freight transport, 1997-2012.

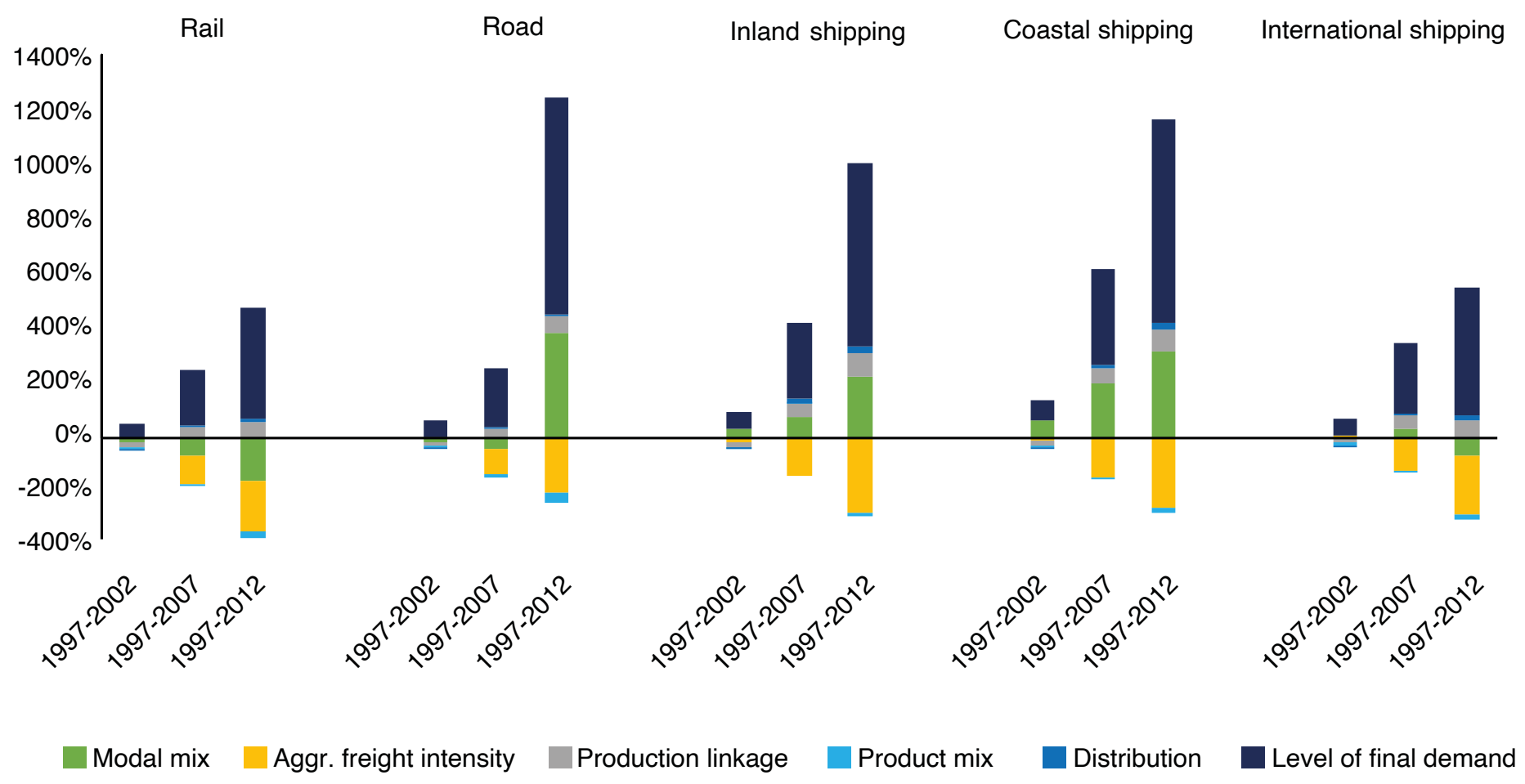

Source: Authors' calculations.

Note: Aggr. = aggregate. 


\section{Analysis of the Latest Trends and Future Scenarios}

S ince 2012, China's economy has been moving in two new directions. On the production side, the country is upgrading its industrial structure and developing high value-added manufacturing and service sectors. These measures are at the core of a number of major policy initiatives, including Made in China 2025, the Supply-Side Structural Reform, and the Belt and Road Initiative. These initiatives are aimed at reducing overcapacity in energy-intensive and environmentally unfriendly industrial sectors such as coal, steel, cement and glass. They also aim to foster the development of knowledge-intensive industries, including information technology, machine tools and robotics, transport equipment, and renewable energy technologies. Likely as a result of these policies, the share of value added of both the machinery, electrical and transport sector and the services sector have continued to increase since 2012 in their respective segment, while the bulk commodity sector's share has decreased (Figure 4).

China's past export- and investment-oriented economic growth model is gradually giving way to a new paradigm in which consumption plays a more important role in boosting domestic growth. Since 2014, consumption has become the largest driver of economic growth against the backdrop of sluggish external demand and slower GDP growth. This increase in consumption is reflected in greater detail in Table 2, which shows that the shares of urban household consumption and government consumption in final demand have risen notably, while exports have had the largest drop. Figure 11 further shows the changes in end users' product expenditure between 2012 and 2017. The largest change during this period is more service expenditure and a smaller share of consumable goods expenditure by rural and urban households and capital formation.

As incomes in China continue to rise, these new trends in the structure of production and final demand may have profound impacts on China's freight transport demand. Figure 14 compares two stages of the Chinese economy with those of the OECD countries to re-illustrate the relationship between economic development and income growth, the economy's final demand and its production structures, and the resultant demand for freight transport. These interrelated factors were previously illustrated in Figure 3.

China has experienced consistently high income growth over the past 30 years, with its 2018 GDP per capita approaching $\$ 10,000$. Household final demand is primarily focused on high-value durable goods (such as vehicles) and housing. Private and public sector investors are primarily focused on infrastructure, other civil work and machinery equipment. The downstream production sectors meeting these demands are mostly located in the central area of the industrial spectrum (see the lower part of Figure 14), namely machinery, electrical and transport and construction. By contrast, in 2000 China's per capita income was $\$ 1,768$. The country's main end users' final demand at that time mainly includes consumption goods, low-value durable goods, housing and infrastructure. The sectors supplying these demands were distributed toward the left side of the industrial spectrum. 
Figure 14. Relationship between income level (2010 constant U.S. dollars [US\$]), end use and production structure, and freight transport demand.

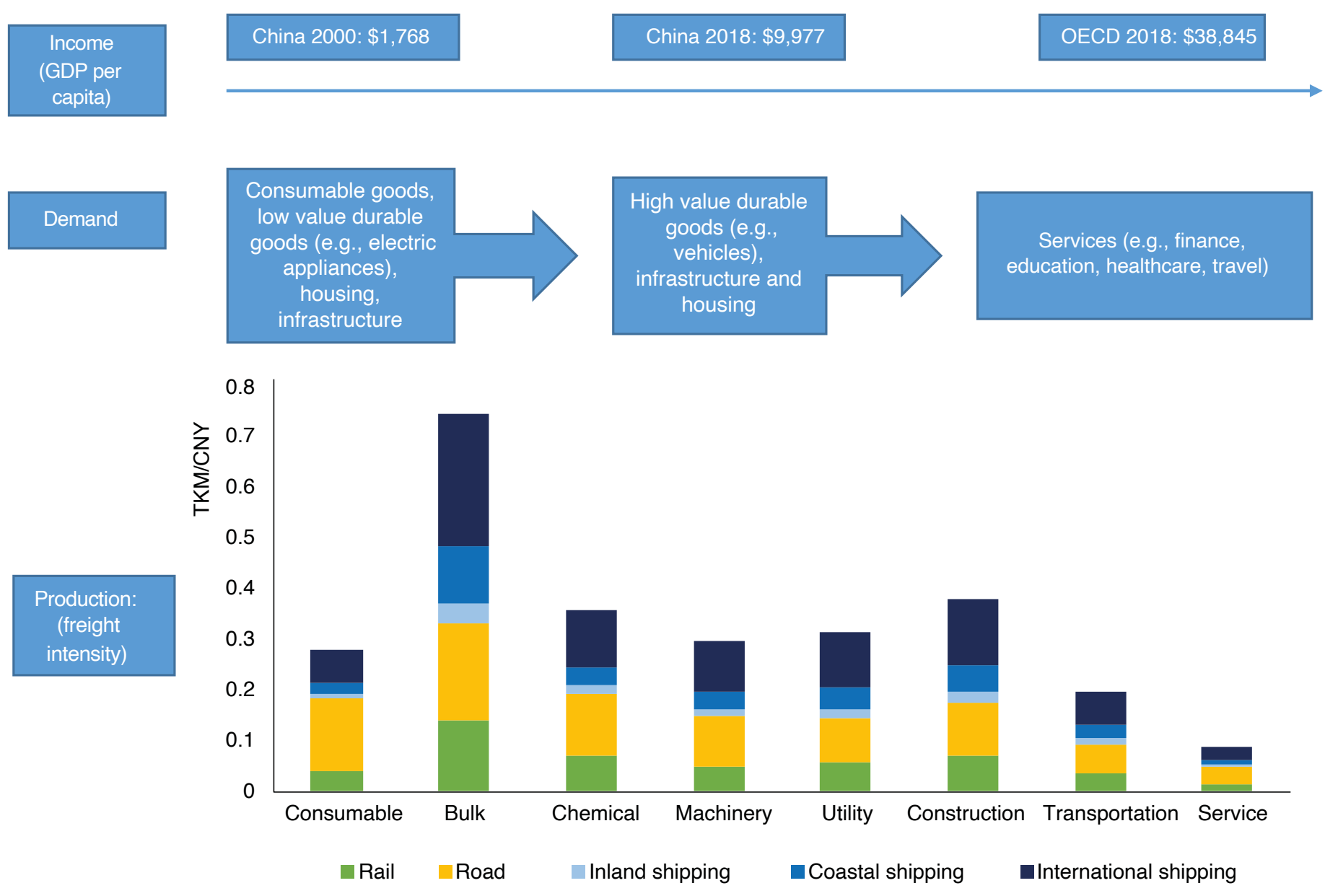

Sources: World Bank (2019) and authors' analysis.

As the Chinese economy continues to grow and as end-user domestic consumption occupies a large role, including a greater expenditure on high value-added manufacturing products and services, it may go through a process of dematerialization. This would see a shift in focus away from freight-intensive sectors such as bulk commodities and construction to less intensive high-end manufacturing and services, located on the right side of the industrial spectrum. However, the impact of this trend toward dematerialization on China's overall freight transport demand may further depend on the relative size of the sectors that the economy is expected to move its focus to.

In light of the ongoing changes in China's economy, this section utilizes the SDA technique to further explore the quantitative impact of the structural determinants on freight transport demand. Using 2012 as the base year, two exercises are conducted to estimate the mode-specific total freight demand for 2017 and 2020, respectively. To estimate the freight volume for 2017, values from the new 2017 China IO table are employed to derive the latest 
estimates of the demand-side variables, including production linkages, final demand structure, end users' product expenditure patterns, and the level of total final demand. These are then used to calculate the mode-specific tkm for 2017. Given the slowdown in the reduction of sectoral freight intensity between 2007 and 2012, its 2017 value is assumed to remain at its 2012 level. For the modal share, the latest mode-specific tkm data suggests that, between 2012 and 2017, the shares of inland and coastal waterway shipping rose, whereas railway and international maritime shipping declined. Therefore, the assumption is made that the variation in modal shares was primarily due to changes in the transport of bulk commodities. Consequently, the value of the bulk commodity freight volume in 2012 is calibrated to match the overall tkm shares by each mode for 2017.

To estimate the 2020 mode-specific tkm, several further assumptions are made:

First, given the consistent expansion of urban household consumption since 2007 , its share is assumed to continue to rise to $30 \%$ in 2020 . The share of exports is reduced to $13 \%$, primarily due to the impact of uncertainty in U.S.-China trade relations. Shares of other final demands are kept unchanged at their 2017 levels (Table 2).

Second, the shares of expenditure on other services by rural and urban households are assumed to grow to $45 \%$ and $54 \%$, respectively, while their expenditure shares on consumable goods decline to $43 \%$ and $30 \%$, respectively (Figure 11). Other end users' product expenditure patterns are kept unchanged at their 2017 levels.
Third, the annual growth of total final demand from 2017-2020 is kept at the same level as the 2012-2017 annual average of $8.17 \%$.

Fourth, production linkages in 2020 remain at their 2017 levels.

Fifth, sectoral freight intensity in 2020 remains at its 2012 levels.

Sixth, in 2018, the State Council of China enacted the "Three-Year Action Plan for Promoting Transportation Structure Adjustment, 2018-2020." Its primary goal was to shift freight movement, especially bulk cargo, from road trucking to railway and waterway shipping (Chen and Xu 2020). Detailed policy objectives include increases in railway and domestic waterway freight shipping by $30 \%$ and $7.5 \%$, respectively, in 2020 compared to 2017 (State Council 2018). The 2017 modal share values are further adjusted to match the $30 \%$ growth target in railway freight volume. More specifically, adjustments to modal shares are assumed to occur only for bulk commodities, with the share of railway use rising to substitute for road trucking. The shares of other modes and other commodity sectors are kept unchanged at their 2017 levels.

Figure 15 presents the estimated tkm for 2017 and 2020 , compared to their actual historical values.

Overall, the estimated $2017 \mathrm{tkm}$ for the five transport modes are all very close to their actual values. The most noteworthy point of the estimated 2020 value is the reversion of rail transport's downward trend since 2012, which grows by 34\% between 2017 and 2020 , thanks to the government's policy of replacing freight trucking with rail transport. The growth in rail is followed by road (24\%), international maritime shipping (20\%), coastal shipping (18\%), and inland waterway shipping (16\%). 
Figure 15. Actual (solid line) and estimated (dash line) mode-specific tkm, 1997-2020.

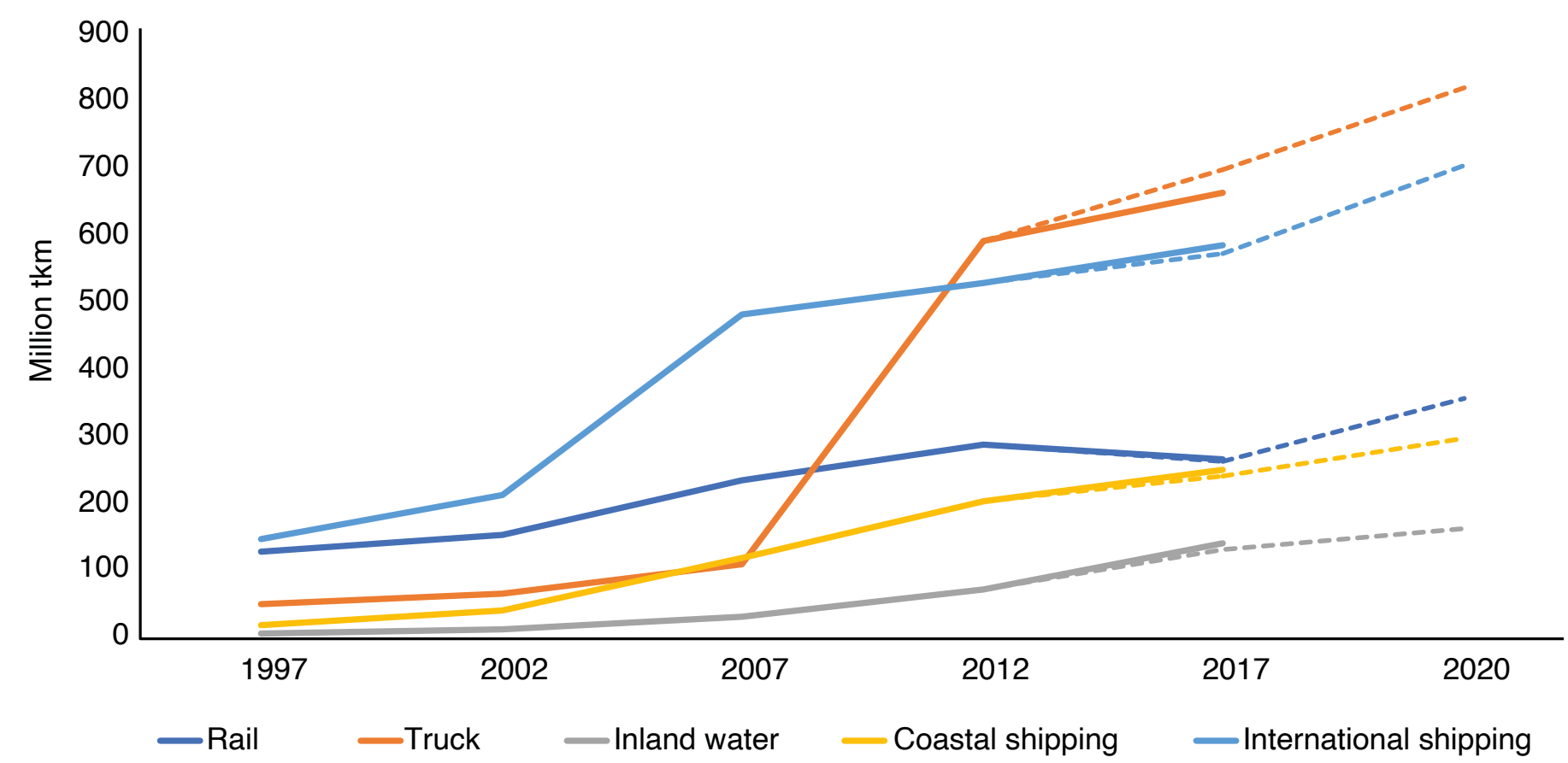

Source: Authors' calculations.

Figure 16. Estimated impacts of various contributory factors on the growth of freight transport, 2017-2020.

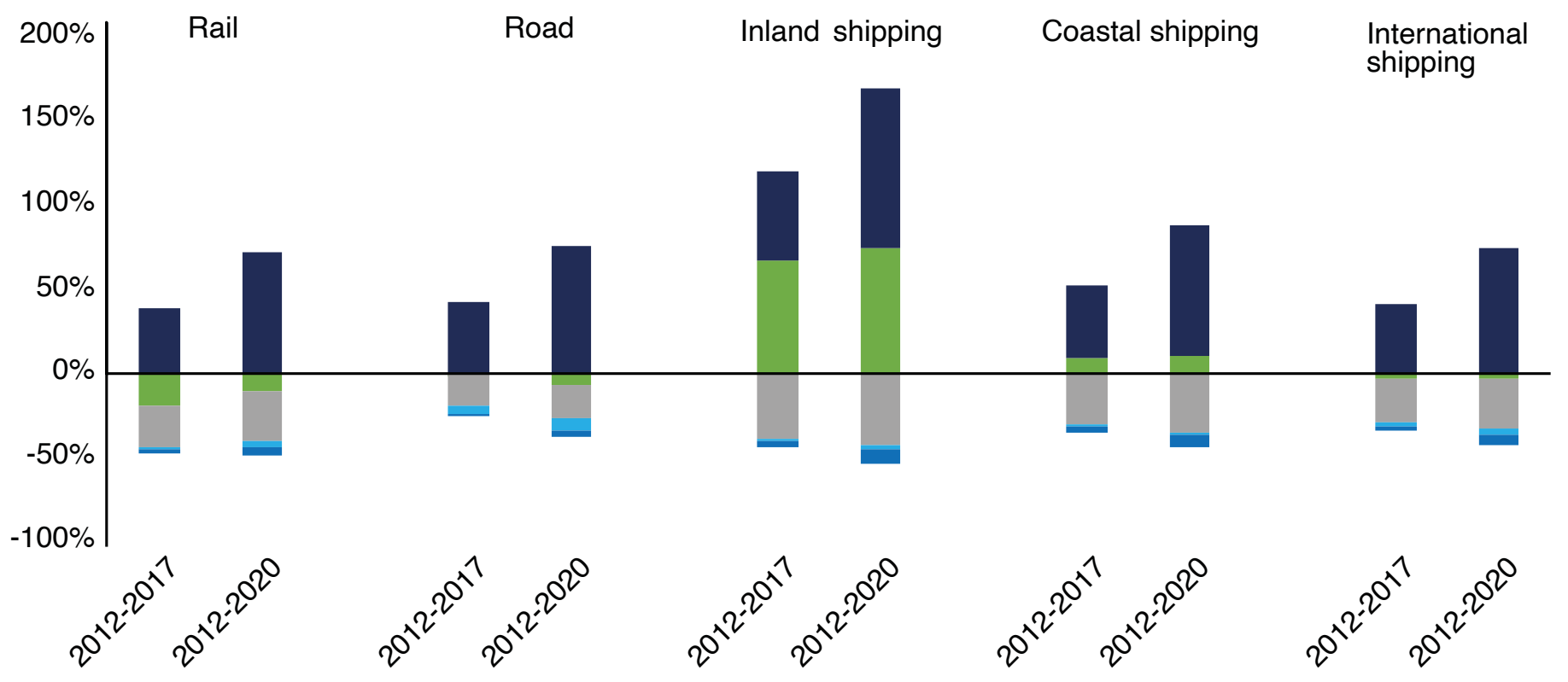

Modal share Total freight intensity

Production linkage

Product mix

Distribution

Level of final demand

Source: Authors' calculations. 
Figure 16 decomposes the estimated changes in total freight volume into separate contributions by the various determinants. Compared to Figure 13, final demand growth remains the largest contributor to the rise in freight volume. However, its impact is much smaller than in the pre-2012 era because the growth of total final demand has slowed considerably since 2012 . Production linkages become the largest negative contributor to freight transport demand. This might be due to reduced demand from the global supply chain as a result of a weak global economic recovery and growing tensions among major trading nations. Another explanation is the rising share of the services sector in China's economy, which requires a shorter supply chain as it involves less exchange of goods. The modal trend suggests a substitution of railway and road trucking for inland and coastal waterway shipping. This is partially in line with the government's policy of boosting freight transport by railway and waterway.
Compared to the other determinants, the quantitative influence of economic structural changes, namely changes in final demand distribution and product expenditure patterns, remains small: their combined effects are around $-5 \%$ in 2017 and $-10 \%$ in 2020 compared to the base year 2012. However, the effects of changes in final demand distribution and product expenditure patterns have turned negative, suggesting that the economy's focus is shifting toward less freight-intensive sectors. However, their relative importance has been gaining. As the Chinese economy settles into a slower pace of growth and moves to a more consumption- and services-led development model, it should be expected that the trend of dematerialization may accelerate in the coming decades and will eventually slow China's overall freight transport demand significantly. 


\section{Conclusions}

ince the late 1990s, China's rapidly growing demand for freight has been one of the leading contributors to global oil consumption and transport $\mathrm{CO}_{2}$ emissions growth. This study employs an extended $\mathrm{IO}$ approach to investigate the roles of economic structural changes and several other essential driving forces of freight transport demand during China's fastest period of freight movement growth. The results show that two main aspects of Chinese economic restructuring, increased investment and export activities and the surging construction and machinery, electrical and transport sectors, have been critical in fueling the rapid rise in the country's freight volume. Further in-depth analysis suggests that the growth of total final demand has been the largest catalyst of freight transport demand, with other factors such as the lengthening inter-industry production linkages in the supply chain and changes in the transport modal mix also playing an important role. These findings are consistent with the underlying investment- and export-driven development model of the economy from 1997-2012, characterized by China's increasing participation in the global production chain, its massive domestic development of property and infrastructure, and the rapid enhancement of its industrial capabilities.

The Chinese economy gradually shifted to a consumption-driven model after 2012, with weak external demand and slower GDP growth. The latest data suggests that the main structural components of its economy have pivoted toward less freight-intensive end-use and production patterns. Decision-makers need to be aware of the pace of this dematerialization trend and its potential impact on freight transport demand.

Several policy implications can be derived from the findings in this research. First, the demand-side factors, i.e., the growth in final demand, production linkage variation, and economic structural changes, have all had significant impacts on freight transport demand. Many of these impacts have outweighed the effects of modal structural changes and freight intensity improvements. For example, lower total final demand growth would be the single largest contributor to slowing aggregate freight transport demand, irrespective of any policy interventions. Therefore, in the face of increasing uncertainties surrounding the global economy, policymakers should account for the potential impacts of the uncertain economic outlook while using supply-side measures to implement carbon emissions mitigation strategies.

Second, as the Chinese economy gradually moves away from a freight-intensive development model toward a focus on higher value-added manufacturing and tertiary sectors, road trucking may increasingly replace railway and waterway shipping, as the latter modes are primarily used for moving low-value and large quantities of bulk goods. This would eventually offset current policy efforts to shift freight movement from trucking to less energy-intensive modes. In view of this, policymakers need to complement existing freight transfer measures by improving the capacities of railways and waterways to ensure the timely transportation of high-value cargo. Developing multimodal transport and facilitating seamless intermodal transfers would strengthen the competitiveness of China's railways and waterway shipping and help to counter the impacts of economic structural changes on modal choices.

Lastly, while dematerialization may imply less overall freight movement in the long run, it does not necessarily translate into reduced energy consumption. Alongside the shifting focus of the Chinese economy, less energy-intensive freight transport modes (e.g., railway and waterway) may be increasingly substituted by more 
energy-intensive modes (e.g., trucks). Therefore, continuing to improve the country's modal mix and transport efficiency remains critically important for decoupling China's freight transport growth from its economic development. More research will be needed on the connection between freight transport demand and energy consumption, opening up an interesting avenue for future work. 


\section{Endnotes}

1 We are very grateful to Nicholas Chase, a former research fellow at KAPSARC, for his contribution to this study and for reviewing this paper.

2 Note that China's IO table follows the competitive imports assumption, where imports are included in the intermediate use and final demands. Therefore, imports are added to the total output to be consistent. See Su and Ang (2013) for more details on the competitive imports assumption in IO analysis.

3 The sectoral output is sourced from the China input-output tables and is denoted in nominal prices.

4 According to the China input-output tables, the value of total final demand is slightly different from that of GDP plus imports, since different treatments of imports/exports are involved when calculating GDP and total final demand.

5 Note that construction is categorized as a non-goods-producing sector since its output cannot be transported directly. Hence, construction as a downstream sector is considered to indirectly use freight transport services for goods produced by its upstream sectors in the supply chain.

6 Unfortunately, freight data by commodity categorization for 2017 is not available. Therefore, only historical freight data from 1997-2012 are used for the main analysis in sections 3 and 4, whereas the 2017 IO data is used to project 2017's freight estimates in section 5.

7 One has also to bear in mind the impact of differences in the methodological treatment of road freight between 2007 and 2012, and, as a result, the possible underestimation of the amount of road freight prior to 2008. See the appendix for more discussion on this.

8 Government consumption has been omitted as its share of embodied freight movement has been less than $5 \%$ on average. 


\section{References}

Alises, Ana, and José Manuel Vassallo. 2015. "Comparison of road freight transport trends in Europe. Coupling and decoupling factors from an Input-Output structural decomposition analysis." Transport Research Part A: Policy and Practice 82:141-157. https://doi.org/10.1016/j.tra.2015.09.013

- - . 2016. "The Impact of the Structure of the Economy on the Evolution of Road Freight Transport: A Macro Analysis from an Input-output Approach." Transport Research Procedia 14:28702879. https://doi.org/10.1016/j.trpro.2016.05.404

Blancas, Luis C., Gerald Ollivier, and Richard Bullock. 2015. "The urgent need of developing multimodal logistics for China's railway sector." (Chinese). Global Financial Times. http:// paper.people.com.cn/gjjrb/html/2015-04/06/ content_1550537.htm

Cascetta, Ennio. 2013. "A Multimodal Elastic Trade Coefficients MRIO Model for Freight Demand in Europe." In Freight Transport Modelling, edited by Vittorio Marzano, Moshe Ben-Akiva, Hilde Meersman, and Eddy Van de Voorde, 45-68. Emerald Group Publishing Limited.

Chen, Shuxue, and Xun Xu. 2020. "China's Green Freight Policy." KAPSARC Commentary.

International Energy Agency (IEA). 2017a. "The Future of Trucks: Implications for energy and the environment."

---. 2017b. "World Energy Outlook 2017."

- - . 2018a. "World Energy Balances 2017."

-_-. 2018b. "World Energy Outlook 2018."
- - - 2019. "Transport: tracking clean energy progress." Accessed September 3, 2019. https:// www.iea.org/tcep/transport/

International Monetary Fund (IMF). 2018. "People's Republic of China: 2018 Article IV Consultation." (press release; staff report; staff statement and statement by the Executive Director for the People's Republic of China, IMF, Washington D.C.).

Leontief, Wassily. 1970. "Environmental Repercussions and the Economic Structure: An Input-Output Approach." The Review of Economics and Statistics 52 (3):262-271. https://doi. org/10.2307/1926294

McKinnon, Alan C. 2007. "Decoupling of Road Freight Transport and Economic Growth Trends in the UK: An Exploratory Analysis." Transport Reviews 27 (1):37-64. https://doi. org/10.1080/01441640600825952

Miller, Ronald E., and Peter D. Blair. 2009. Input-Output Analysis: Foundations and Extensions. 2nd ed. Cambridge: Cambridge University Press.

National Bureau of Statistics. 2019. Input-Output Tables of China. http://data.stats.gov.cn/ifnormal. $\mathrm{htm}$ ?u=/files/html/quickSearch/trcc/trcc01. $\mathrm{html} \& \mathrm{~h}=740$

National Bureau of Statistics. 2019. China Statistics Yearbook 2019. http://www.stats.gov.cn/tjsj/ ndsj/2019/indexch.htm

Nealer, Rachael, Christopher L. Weber, Chris Hendrickson, and H. Scott Matthews. 2011. "Modal freight transport required for production of U.S. goods and services." Transport Research Part E: Logistics and Transport Review 47 (4):474-489. https://doi.org/10.1016/j.tre.2010.11.015 
State Council. 2018. "Three-Year Action Plan for Promoting Transportation Structure Adjustment 2018-2020." (Chinese). http://www.gov.cn/zhengce/ content/2018-10/09/content_5328817.htm

Su, Bin, and B. W. Ang. 2012. "Structural decomposition analysis applied to energy and emissions: Some methodological developments." Energy Economics 34 (1):177-188. https://doi. org/10.1016/j.eneco.2011.10.009

- - . 2013. "Input-output analysis of CO2 emissions embodied in trade: Competitive versus non-competitive imports." Energy Policy 56:83-87. doi: https://doi.org/10.1016/j.enpol.2013.01.041

Su, Bin, B. W. Ang, and Yingzhu Li. 2017. "Input-output and structural decomposition analysis of Singapore's carbon emissions." Energy Policy 105:484-492. doi: https://doi. org/10.1016/j.enpol.2017.03.027

Tavasszy, Lorent, and Gerard De Jong. 2014. Modeling Freight Transport. Elsevier
Wang, Baoan. 2015. "Understanding economic structural change based on estimates of electricity consumption and railway freight movement." (in Chinese). People's Daily. accessed at http://cul. chinanews.com/cj/2015/10-08/7557402.shtml

World Bank. 2019. World Development Indicators. https://databank.worldbank.org/source/ world-development-indicators

Xu, Ming, Ran Li, John C. Crittenden, and Yongsheng Chen. 2011. "CO2 emissions embodied in China's exports from 2002 to 2008: A structural decomposition analysis." Energy Policy 39 (11):7381-7388. doi: https://doi.org/10.1016/j. enpol.2011.08.068

Yu, Haitao. 2018. "A review of input-output models on multisectoral modelling of transport-economic linkages." Transport Reviews 38 (5):654-677. https:// doi.org/10.1080/01441647.2017.1406557 


\section{Appendix}

The Chinese statistical authorities publish a detailed input-output table every five years. The data for 1997, 2002, 2007, 2012 and 2017 are reported in current producer prices, and cover 124, 122, 135 , 139 and 149 sectors, respectively. China revised the industrial classification codes for its IO tables in 2002, 2011 and 2017. Given the broad definition of the eight-sector categorization used in this paper and the high resolution of the IO statistics, the data can be aggregated into the desired categorizations without introducing additional assumptions.

Compared to the IO data, China's freight transport statistics are less consistently available. While the IO data is from 1997-2017, data for freight is available or can only be imputed up to 2012 , because information on the commodity breakdown of road freight is missing for the most recent years.

Depending on the type of data treatment applied in this paper, the data for freight can be divided into three sources: railway, road, and waterway shipping (including inland, coastal and international shipping). Annual statistics on railway freight transport by commodity are available. However, the data only report tkm for overall freight movement as well as 13 of the most shipped commodities, necessitating an estimate of the tkm for the remaining commodity categories. To accomplish this, the commodity classification code for railway freight statistics is first compared to the industrial classification code of the
IO table. ${ }^{9}$ The values of railway transport services required for these commodity sectors (obtained from the $\mathrm{IO}$ table) are then used to allocate the remaining uncategorized railway freight movement. ${ }^{10}$ In a few cases, one IO sector maps to multiple railway freight commodity sectors, and assumptions are then made to evenly distribute the value of the railway freight service input among the subsectors.

\section{Statistics on China's road freight transport} categorized by commodity type are reported by the Yearbook of China Transport and Communications up until 1998. From 1999, the national statistics were discontinued. Various road freight transport data are available at the provincial level. However, they are neither consistent over time nor representative across geographies, making it difficult to infer a national average distribution from the summation of regional totals. Two subsequent national road freight transport statistics with commodity breakdowns are available after the Ministry of Transport conducted dedicated special surveys for highway and waterway transport in 2008 and 2013. ${ }^{11}$ In view of the data scarcity, existing data are used to extrapolate the data for the missing years. Similar to the railway freight data, the road freight statistics only report values for some important commodity types and overall road freight. Therefore, a similar approach, as was applied in the treatment of the railway freight data, is used to allocate the unspecified tkm

\footnotetext{
${ }^{9}$ China's railway freight statistics are organized by its National Central Product Classification and Codes, which is similar to the United Nations' (UN's) Central Product Classification (CPC) standard. The industrial classification code for China's IO table is based on the UN's International Standard Industrial Classification of All Economic Activities (ISIC) Rev. 3 and Rev. 4.

${ }^{10}$ Nealer et al. (2011) further divide the value of purchased transport services by an assumed average freight rate (dollar per $\mathrm{tkm}$ ) to calculate freight transport. However, this step does not feature in this paper due to the absence of reliable railway freight rate data. The same applies to the treatment of road and waterway freight data.

${ }^{11}$ The sample coverage of road freight vehicles in the 2008 special survey for highway and waterway transport is different from the previous years, resulting in a dramatic increase of total road tkm compared to 2007. However, it is unclear to what extent the relative share of road freight movement is underestimated compared to other modes in the years prior to 2008.
} 
to the remaining commodity categories. ${ }^{12} \mathrm{~A}$ linear interpolation of the commodity distribution is then taken to calculate the distribution for the missing years 2002, 2007 and 2012, using the data available for the other years.

Last, China reports total annual tkm for domestic inland, domestic coastal, and international maritime shipping separately, but it does not disclose the commodity distribution for each mode. In the absence of such information, commodity distribution data for principal inland and coastal port turnover are used instead. For 2007 and 2012, the port turnover data differentiate between domestic and international trade. Hence, the international portion of both inland and coastal ports are used to extract commodity distribution data for international maritime shipping. For domestic coastal shipping, the domestic portion of coastal port turnover is used. And for inland waterway, total inland port turnover data (including domestic and international trade) are used. The 1997 and 2002 port turnover data do not offer a domestic/international breakdown. Therefore, the commodity distribution of inland and coastal port freight turnover is applied directly for inland and coastal waterway shipping. In the absence of national statistics on port turnover for international trade in 1997 and 2002, data reported for the 25 principal ports of the Yangtze River is used instead. ${ }^{13}$

\footnotetext{
${ }^{12}$ China's road freight statistics are organized by the Classification and Codes of Transport Cargo, which differs from the industrial classification code for the IO table, as well as the National Central Product Classification and Codes for the railway freight statistics. Therefore, similar to the treatment of the railway freight data, a detailed comparison of both the road freight and the $\mathrm{IO}$ table classification standards is conducted when homogenizing the data.

${ }^{13}$ The Yangtze river is China's largest and busiest inland waterway. The total turnover of its 25 principal ports accounts for nearly half of China's total inland port turnover. Unlike China's national statistics, statistics for the Yangtze river do offer a domestic/international trade breakdown.
} 


\section{Notes}

.

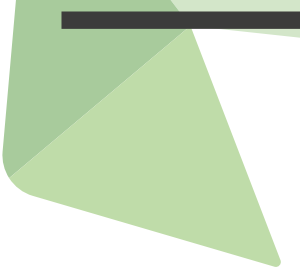




\section{About the Authors}

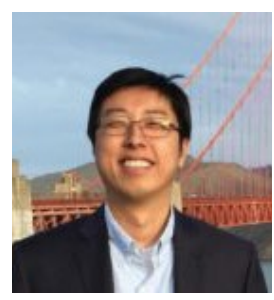

\section{Xun Xu}

Xun Xu is a research associate leading KAPSARC's China/India future transport energy demand project. His research interests include freight transportation, development economics, population economics and the Chinese economy. He is also responsible for KAPSARC's efforts in evaluating the macroeconomic impact of demographic change in the Kingdom of Saudi Arabia. Prior to joining KAPSARC, he worked at the East West Center and at the NREM department of the University of Hawaii. As a trained population economist, he is also a member of the National Transfer Accounts network.

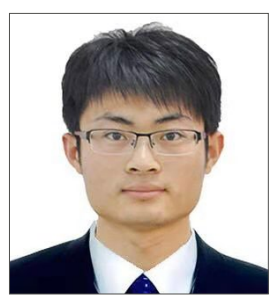

\section{Tianduo Peng}

Tianduo Peng is a researcher at China National Petroleum Corporation Economics and Technology Research Institute. He previously worked for KAPSARC as a research intern.

\section{About the Project}

China has witnessed substantial freight transport energy consumption growth in the past 20 years, and it is expected to continue to be a significant contributor to global transport oil demand in the coming decades. However, the changing structure of the Chinese economy, as well as recent development in the country's logistical freight sector suggest that the future growth of freight transport oil demand in China may not be as strong as before. As China is one of the most important buyers of petroleum products from Saudi Arabia, this project seeks to use state-of-the-art modeling approaches and data sources to develop a next generation freight transport energy demand model. This model will help to understand the latest trends in China's freight transport oil demand. 
INAPSARC

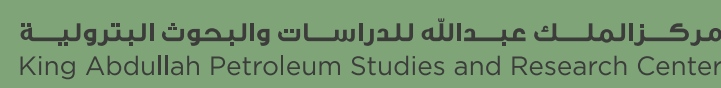

www.kapsarc.org 